Becq, A., Chèze, D., 2021. Influence of mixing valve dynamics and recirculation loop connection to solar tank on large hot water system performances. Solar Energy 218, 211-225. https://doi.org/10.1016/j.solener.2021.02.012

Soar Energy journal website : https://doi.org/10.1016/j.solener.2021.02.012

Accepted manuscript version 


\title{
Influence of mixing valve dynamics and recirculation loop connection to solar tank on large hot water system performances
}

\section{Arnaud Becq ${ }^{\mathrm{a}}$ and David Chèze ${ }^{\mathrm{a}}$}

Corresponding author: David Chèze, david.cheze@cea.fr

a. CEA, LITEN, F-38054 Grenoble, France

\begin{abstract}
A centralized solar domestic hot water system for a multi-family building is analyzed numerically. The solar preheated water in the solar tank is flowing into an auxiliary tank, connected to a gas boiler. At its output, a mixing device is used to ensure hot water at steady temperature before going through the recirculation loop. This reference system is sized as a typical installation under mild climate in France. The load profile is generated statistically with a one-minute time step. Small time scale phenomena have consequences on the global system behavior: recirculation flow rate variations due to pressure drop change is modeled and validated experimentally. This work's goal is to analyze these effects on two sub-parts of the plant: mixing valve and recirculation loop connection to solar storage. In each case, yearly simulations with 6 seconds time step provide quantitative performance indicators for different sizing and control options. Results show that mixing valve slow response, due to ageing or bad design, leads to a loss of $3.5 \%$ energy savings compared to using a fast component. Furthermore, health risks increase as the minimal temperature in the recirculation loop is often under $50^{\circ} \mathrm{C}$, which promotes legionella development due to cold water plug flows generated in the loop by the mixing valve dynamic response. The recirculation loop, linked to a solar tank, leads to performance improvement with $6 \%$ to $15 \%$ increase in energy savings following solar oversizing and reduced overheating risks.
\end{abstract}

Keywords: Solar Heating System, Recirculation Loop, Mixing Valve, High Time Resolution Profiles, Experimental Measurements

\section{Highlights}

- A dynamic model for transient recirculation flow rate is developed, experimentally validated allowing multi-criteria evaluation of the results

- Slow mixing valve lowers energy savings and promotes legionella development through cold plug flow generation

- Increasing the auxiliary set-point (by $5^{\circ} \mathrm{C}$ above the water flow set point temperature) reduces the overall energetic performance (by 10\%), increases the sanitary risk and lowers the system durability

- Solar thermal collector field oversizing combined with connection of the recirculated water loop to the solar tank leads to increased overall energetic performance. However, system durability risks are greater due to solar tank cooling self-limitation phenomenon

\section{Introduction}

Global warming is a reality that already has serious consequences in the world as reported in the fifth IPCC (Intergovernmental Panel on Climate Change) report (IPCC, 2014). In this context, limiting greenhouse gas emissions, especially in energy production industry, is a necessity. In that sense, solar energy is found for years to be an appropriate solution for hot water generation because, unlike space heating, the domestic hot water (DHW) demand remains roughly constant throughout the year to be covered by profusely available solar resource during the summer season. Yet, the worldwide solar thermal collector area installed per year is declining since 2012 (SHC - IEA, 2018), while heat pumps associated with photovoltaic panels are expanding quickly $(+7 \%$ heat production increase in 2017 compared to 2016) and modern bioenergy represents $70 \%$ of renewable heat production in 2017 (IEA, 2018).

In order to improve solar thermal competitiveness, the French solar professional association (ENERPLAN) and Environment and Energy French Agency (ADEME) discussed the oversizing of the solar thermal field in 
comparison with DHW user demand, to cover part of the thermal losses of the DHW recirculation loop (Porcheyre, 2017). However, this approach raised several interrogations about the overheating risk, durability of the installation, solar thermal collector productivity and overall SDHW (Solar Domestic Hot Water) energetic performance gains. Moreover, some failures happened during the past decades in SDHW plant either at design, installation or operation phases that led to degraded system performances and damaged the SDHW reputation in solar thermal plant owners' opinion.

Thus, many challenges come from these systems, among which can be mentioned the energetic performances or the legionella risks (COSTIC, 2014). Thanks to a measurement campaign on several SDHW systems, anomalies have been put forward such as low measured solar fractions (Porcheyre, 2017). In addition, a long term large SDHW plants performance monitoring program started in 2007 raised some concerns about DHW mixing valve role in abnormally low fraction of water flowing through the solar tank compared to the total DHW use (Pradier, 2018). Furthermore, ADEME is currently funding a project named "Legiosol" to evaluate legionella development risks on SDHW systems. It starts with the concern about risk of actual legionella developments in installation fulfilling current regulation (COSTIC et al., 2019).These solar DHW systems have been studied for decades through modeling (Hobbi and Siddiqui, 2009; Shrivastava et al., 2017), yet answers to these last concerns are not developed in previous simulation studies from the literature.

The typical SDHW system considered in this work showing its main components is presented in Figure 1. This typical design is recommended for buildings with large DHW consumption by SOCOL, French association of solar heat professionals (SOCOL, 2017). Solar heat is carried from solar collectors to an external heat exchanger in the solar loop. This energy is stored in the solar tank through the preheating of coming cold water. The solar loop hydraulic pump is turned on when solar tank bottom water is colder than the heat transfer fluid at solar collectors' output. In order to reach a defined temperature even when solar production is not sufficient, a gas boiler is required to heat up the water to the set temperature. A mixing device is usually installed downstream of the auxiliary tank to ensure that the DHW temperature remains constant. In multi-family buildings, since DHW production system can be located far from the user, a recirculation loop bringing constantly hot water close to the user is required to avoid waiting for the hot water moving from the tank through the pipes between the mixing device to the draw-off endpoints.

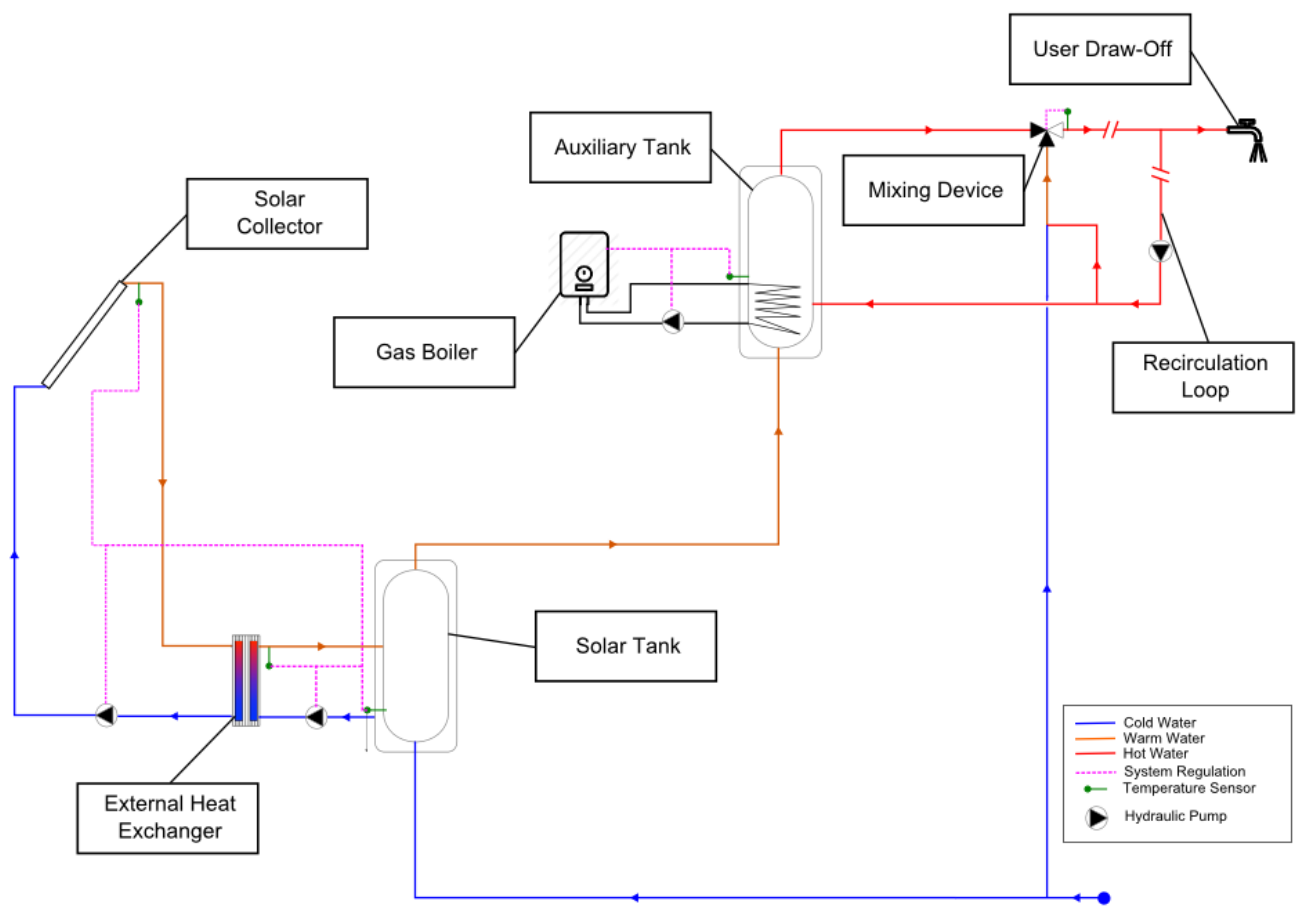

Figure 1 - Centralized solar domestic hot water system design and main components - Reference system

As previously mentioned, SDHW system performances in operation may perform under the expectations for various reasons. Since the solar collector and water tank are the key components that procure energy savings in a SDHW system, the possible causes of reduced overall system performance in real dynamic operation were 
previously tracked in priority to these components rather than to heat distribution circuit. Indeed, it has been shown that preserving stratification inside the water tank improves the energy recovery from the solar loop (Kim et al., 2016). For these reasons tank stratification has been extensively studied and modeled in addition to developing different technical solutions to address this issue, for instance the water snake (Al-Habaibeh et al., 2018) or horizontal obstacles inside the water tank (Altuntop et al., 2005). Solar collectors types have also been numerically compared (Dongellini et al., 2015) and CFD simulation (Computational Fluid Dynamics) has shown the dynamic phenomena occurring inside solar collector tubes (Gunjo et al., 2017). On the other hand, the mixing device and recirculation loop have not been as much investigated and these two components have been recently pointed out as potential causes of anomalies in several SDHW systems for instance in Grenoble region, France (Ramonet and Sahraoui, 2018). Therefore, this work focuses first on these two subsystems and shows that they influence significantly SDHW system performance, as they impact the whole system's dynamic response such as tank stratification through recirculation loop flow.

Then, another major topic that is not fully developed in the literature is the connection impact of the recirculation loop to the solar tank. SOCOL explains that it can improve the system energy performance as solar production provides a part of the recirculation losses (SOCOL, 2017), which can exceed $35 \%$ of the total incoming energy (Ghorab et al., 2017). Previous static model of centralized DHW system with recirculation connection to solar tank has shown a $4 \%$ reduction of auxiliary energy consumption for an eight days period (Prapas et al., 1993). Moreover, adding colder fluid to the solar tank helps reducing the overheating risk. Optimal control of the recirculation pump has been studied in American buildings (Dentz et al., 2016). However, these rules tend to lower the recirculation loop minimal temperature which favors legionella development.

In (Papillon et al., 2014), linked to the SCHEFF project, the authors present a comparison of centralized SDHW system model with recirculation loop (like in Figure 14) versus an original "umbrella" distribution to avoid the traditional recirculation loop heat losses. In (Lämmle et al., 2017), the authors presents an alternative DHW recirculation loop modeling in a multifamily house building. The hot water is prepared from a solar heated buffer tank through an external plate heat exchanger. Without details regarding this part of the simulation that was not in the core of the work, the recirculation flow is supposed constant and summed to draw-offs flow rate similarly to previous existing approach. The same model is applied in (Bernardo et al., 2012), where recirculation pump TRNSYS Type $3 b$ ensures a constant flow, independently of external effects such as water draw offs.

Recirculation loop impacts all current concerns mentioned before, which justifies the need to develop a dynamic model to better understand and quantify its effects on system performance. The results obtained with this model are necessary to address these challenges through adapted design rules.

Static models can't reproduce the real dynamic behavior of the mixing valve nor the dynamically variable flow rates inside the recirculation loop according to the intensity of user's water draw-offs. That is why, using TRNSYS, we developed a dynamic model for SDHW systems, with a focus on these two components. The literature survey performed in this work did not issue detailed investigations of the dynamic of the mixing valve and recirculation loop in SDHW plant. Yet, measures on real systems introduced later in this article have shown that mixer opening keeps changing on a small time-scale. Thus, it is necessary to simulate such behavior to understand its consequences.

The goal of this work is to explore physical phenomena around hot water mixing valves and recirculation loop in SDHW system that could cause performance degradations evaluated following energetic, sanitary regulation compliance, user comfort and durability criteria. These investigations were performed with SDHW dynamic TRNSYS ("TRNSYS," n.d.) simulations at high time resolution using newly developed recirculation loop component. This model has been validated experimentally. Finally, the parametric simulation study gives insight about design consequences on SDHW system performances. 


\section{Developments:}

As explained in the introduction, the main model developments concerned two specific components of SDHW systems which are not usually dynamically modelled: the mixing device and the recirculation loop. Then, the reference system model and sizing is described with its own numerical validation. Lastly, the multiple performance indicators used for the parametric study are listed.

\subsection{Mixing device and recirculation loop models}

\subsubsection{Model developments}

There are two major mixing valve technologies: thermostatic mixer and motorized three-way valve with temperature sensor at the outlet and appropriate controller. The influence on overall SDHW system performance of the dynamic response of such component has not been studied in the past. Thus, no obvious dynamic response model was available in the literature.

The response times of these components are not available from manufacturer detailed datasheets. Yet, EN 15092, that applies on such mixing device, requires an output temperature error of $3^{\circ} \mathrm{C}$ in less than 30 seconds for various tests (AFNOR, 2008). Because of aging and wear, the response time might increase and this work analyzed such effects on system performances by a first order approximation detailed in the following section. An existing internal user model (Type 953), developed by CEA and used in national research project SCHEFF, determines the needed repartition to provide water at the set temperature using the input temperatures and total mass flow. The model is static which represents an ideal valve with immediate response time and it is similar to the combination of Type 11 and Type $11 \mathrm{~b}$ from the TRNSYS Standard library.

However, dynamic response time is not considered with previous model. That's why, in this work, mixer dynamic is modeled as first order system response, as explained in the introduction. A Proportional Integral (PI) controller (Type 23) is added to react to the temperature difference between instantaneous mixer output $\left(T_{\text {mix }}\right)$ and set point $\left(T_{\text {set }}=55^{\circ} \mathrm{C}\right)$. The mixing valve response to this error is:

$$
\begin{array}{ll}
c(t)=K\left(e(t)+\frac{1}{T_{i}} \int_{0}^{t} e(\tau) d \tau\right) & (\text { Eq 1) } \\
e(t)=T_{\text {mix }}-T_{\text {set }} & (\text { Eq } 2)
\end{array}
$$

The proportional coefficient $K$ is constant and set at 1 to ensure model stability and to avoid oscillations in the response. Integral time coefficient, $T_{i}$, enables the variation of the response time. The values are gathered in Table 1. The first two response times, 0.5 and 1 minutes, represent well designed three-way motorized valves and fast thermostatic mixers. 2, 6 and 10 minutes stand for badly manufactured or ageing thermostatic mixers. In this work the response time is taken as the time to reach $95 \%$ of the final value when a $600 \mathrm{~L} / \mathrm{h}$ draw-off occurs. The simulation time step is set to 0.1 minute. The first three mixing devices fulfill the national regulation (AFNOR, 2008) while the slowest two do not.

\begin{tabular}{|c|c|c|}
\hline 95\% response time (min) & $\mathbf{K}(-)$ & $\boldsymbol{T}_{\boldsymbol{i}}(\mathbf{h})$ \\
\hline 0.5 & 1 & 0.0005 \\
\hline 1 & 1 & 0.001 \\
\hline 2 & 1 & 0.0022 \\
\hline 6 & 1 & 0.0075 \\
\hline 10 & 1 & 0.011 \\
\hline
\end{tabular}

Table 1 - PI parameters for different mixing valve response times

The second model developed in this work deals with the pressure losses in the recirculation loop. When there is no draw-off, a nominal recirculation flow rate of $500 \mathrm{~L} / \mathrm{h}$ was considered. However, the pressure drops between the mixing valve and the delivery increase when a draw-off occurs due to the higher fluid speed in pipes. As the differential pressure at the recirculation pump is increasing, the recirculation flow rate decreases following the pump characteristic.

The goal of this study is to quantify this phenomenon potential impact on multiple system performance criteria ranging from energy efficiency to regulation compliance. For example, regulation requires that a minimum 
temperature is maintained everywhere in the recirculation loop, to prevent legionella development. During drawoff, pressure losses are greater than nominal state, which means that the return flow is slower, thus suffering higher thermal losses. The regulation might then not be fulfilled in specific scenario as return temperature might be under the requirement. Even if TRNSYS standard Types have often been used to model SDWH systems in the past ((Dickinson et al., 2013; Missoum et al., 2016)), some limitations to its regular library remain as pressure drops are not included (Shrivastava et al., 2017). Therefore, a new TRNSYS Type has been developed using TRNSYS Studio in Fortran. This model adapts at each time step the recirculation flow rate to pressure drops in the loop. Model validation has been reached through experimentation on running installation in Chambéry, France.

A new type, Type ${ }^{\circ} 999$ is created with TRNSYS 18 TypeStudio. It takes as input the draw-off flow rate, the recirculation loop characteristics and the pump characteristic. Three pressure drops are computed:

- Regular pressure drops from friction between the mixing valve and the delivery

- Regular pressure drops from friction in the return part of the recirculation loop

- Singular pressure drops

The first two are calculated with the following equation (Recknagel et al., 2005), directly implemented in Type n 999 Fortran code:

$$
\Delta P_{\text {reg }}=f\left(\operatorname{Re}_{D}, \frac{\varepsilon}{D}\right) \frac{L}{D} \frac{\rho v^{2}}{2}
$$

With:

- $\Delta P_{\text {reg }}:$ Pressure drop $(\mathrm{Pa})$

- $\quad L$ : Pipe length (m)

- $\quad D$ : Pipe hydraulic diameter (m)

- $\quad \rho$ : Fluid density $(\mathrm{kg} / \mathrm{m} 3)$

- $\quad v$ : Flow speed $(\mathrm{m} / \mathrm{s})$

- $\varepsilon$ : Pipe roughness $(\mathrm{m})$

- $R e_{D}=\frac{v D}{v}:$ Reynolds number (-)

- $\quad f$ : Friction coefficient determined iteratively with Colebrook equation:

$$
\frac{1}{\sqrt{f}}=-2 \log \left(\frac{\varepsilon / D}{3,71}+\frac{2,51}{R e_{D} \sqrt{f}}\right) \quad(\mathrm{Eq} 4)
$$

The last one, singular pressure drops, can be modelled by the following law, with $x$ determined by the quantity and types of singular pressure drops in the recirculation loop and with $Q_{r e c}$ the recirculation flow after relaxation:

$$
\Delta P_{\text {sing }}=x\left(Q_{\text {rec }}+Q_{\text {draw-off }}\right)^{2} \quad(\text { Eq 5) }
$$

This value is hardly obtainable on existing DHW distribution circuit already integrated in real building, therefore we have considered singular pressure drops from the mixing device only. The curve for GN1 from (THERMADOR, 2017) leads to:

$$
\Delta P_{\text {sing }}=8\left(Q_{\text {rec }}+Q_{\text {draw-off }}\right)^{2} \quad(\text { Eq 6) }
$$

By summing the three contributions, the total pressure differential at the pump (Eq 8) leads to a reduced return flow rate $Q^{\prime}{ }_{r e c}(\mathrm{Eq} 8)$.

$$
\Delta P_{\text {tot }}=\Delta P_{\text {reg-toDelivery }}+\Delta P_{\text {reg-return }}+\Delta P_{\text {sing }} \quad(\text { Eq 7) }
$$

A standard pump flow rate/pressure characteristic is approximated with a parabolic function:

$$
Q_{r e c}^{\prime}=a \Delta P_{t o t}^{2}+b \Delta P_{t o t}+c
$$

With $a, b$ and $c$ polynomial coefficients. 
An iterative solver is developed to get the recirculation flow rate as the solution of the equations (7) and (8) as the problem is coupled. Indeed, a variation in the recirculation flow impacts the pressure drops. With new pressure drops, the recirculation flow needs to be computed again. A relative tolerance criterion is set at 0.0001 and around 100 iterations are usually needed for the recirculation flowrate to converge. A relaxation factor $\omega$ of 0.1 is used to ensure convergence:

$$
Q_{r e c}(t+\Delta t)=\omega Q_{r e c}{ }^{\prime}(t+\Delta t)+(1-\omega) Q_{r e c}(t)
$$

With $Q_{\text {rec }}{ }^{\prime}$ being the recirculation flow solution before relaxation.

The configuration of exhaustive singular pressure drops is not foreseen in this model (pipe turns, Tee pieces...), yet its potential impact on system performance, when aiming at the comparison with a real installation, can be accounted by estimation of additional equivalent regular pressure drops as suggested by empirical rules in (Recknagel et al., 2005).

Figure 2 shows that during draw-off (in pink - dotted line), the recirculation flow (in orange - full line) decreases, as expected. This phenomenon was not accounted in previous models and should be considered during recirculation loop design phase. The newly developed model mechanism is represented in Figure 3.

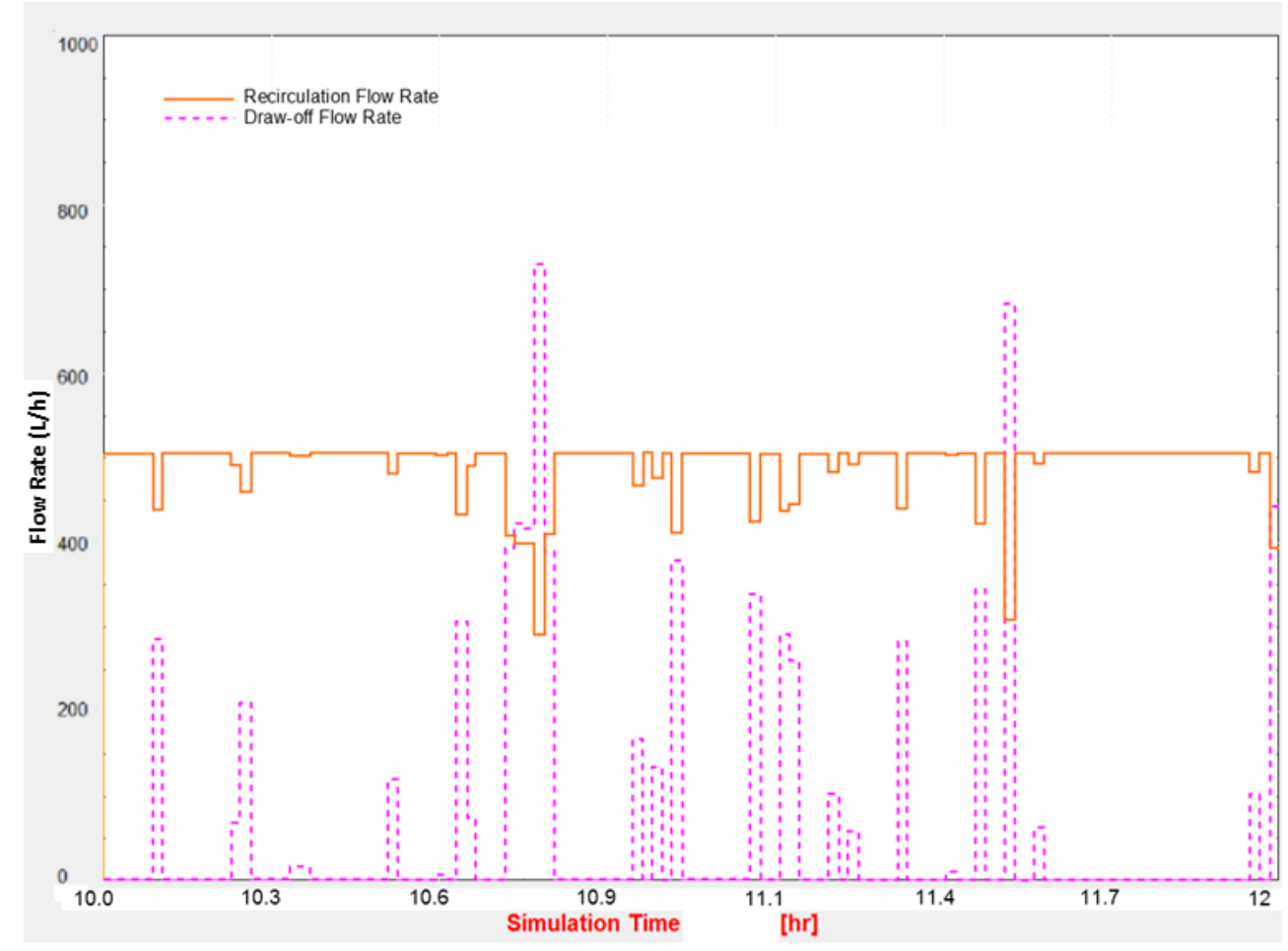

Figure 2 - Draw-off flow rate (pink - dotted line) and recirculation flow (orange - full line) for 2 hours in January $1^{\text {st }}$ with the reference system 


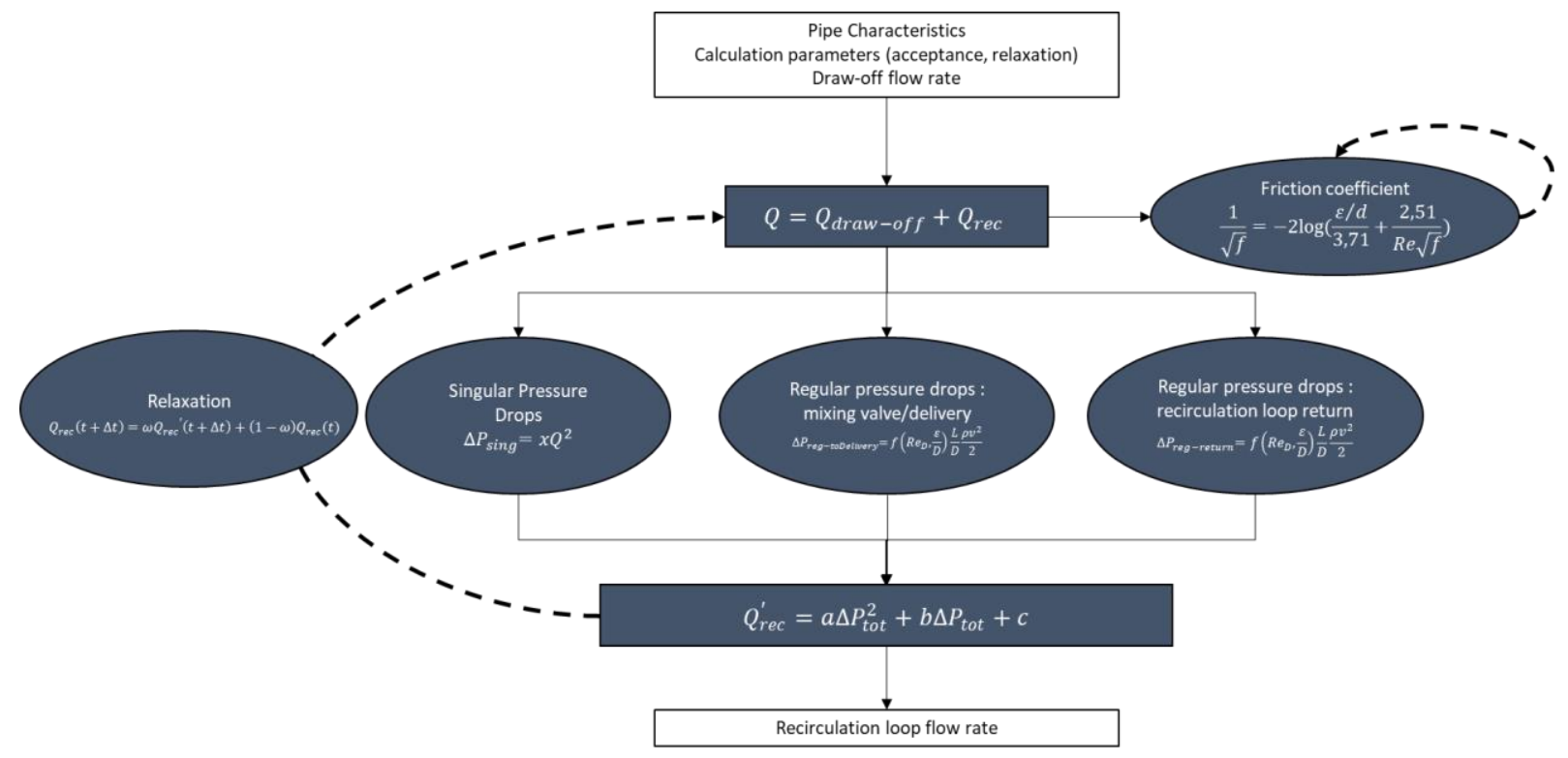

Figure 3 - Newly developed Type $\mathbf{n}^{\circ} 999$ model

\subsubsection{Experimental validation of Type $n^{\circ} 999$}

An experiment is set up to validate the newly developed recirculation Type ${ }^{\circ} 999$. It focuses on flow measurement in a real, running since 2011, large centralized solar thermal plant in Chambery, France, that provides DHW to 6 inter-connected buildings with 80 apartments in total. A recirculation loop is required when considering the distance (about 150 meters) between the heating system and the furthest apartment. Non-intrusive ultrasonic flowmeters are installed in different locations as shown in Figure 4. The sensor measurement principle is detailed in (Szebeszczyk, 1994). We paid particular attention to the recommended installation guidelines such as minimal straight pipe lengths before and after the flow sensors.

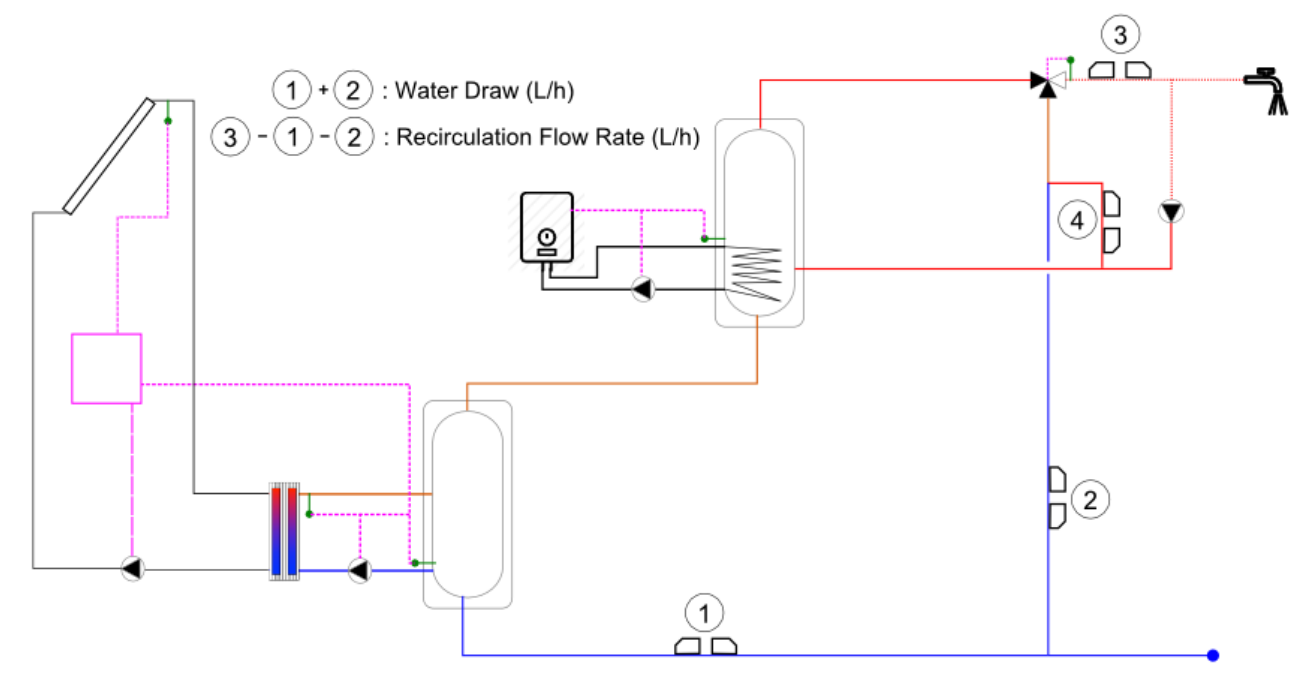

Figure 4 - Hydraulic layout of the experimental SDHW system

The main goal of this experiment is to verify recirculation loop flow rate dependency to the flow rate of the water draws. A real installation was chosen so that the real impact of dynamic water draws can be studied. The four installed flowmeters enable to calculate these two flows. Indeed, adding sensors 1 and 2 measures leads to the water draw value. The flow in 3 is the sum of the water draw and the recirculation flow. It thus provides the latter. A flow measurement is recorded every 10 seconds for 48 hours. As a result, the recirculation flow dependency to the water draw can be represented in Figure 5. 


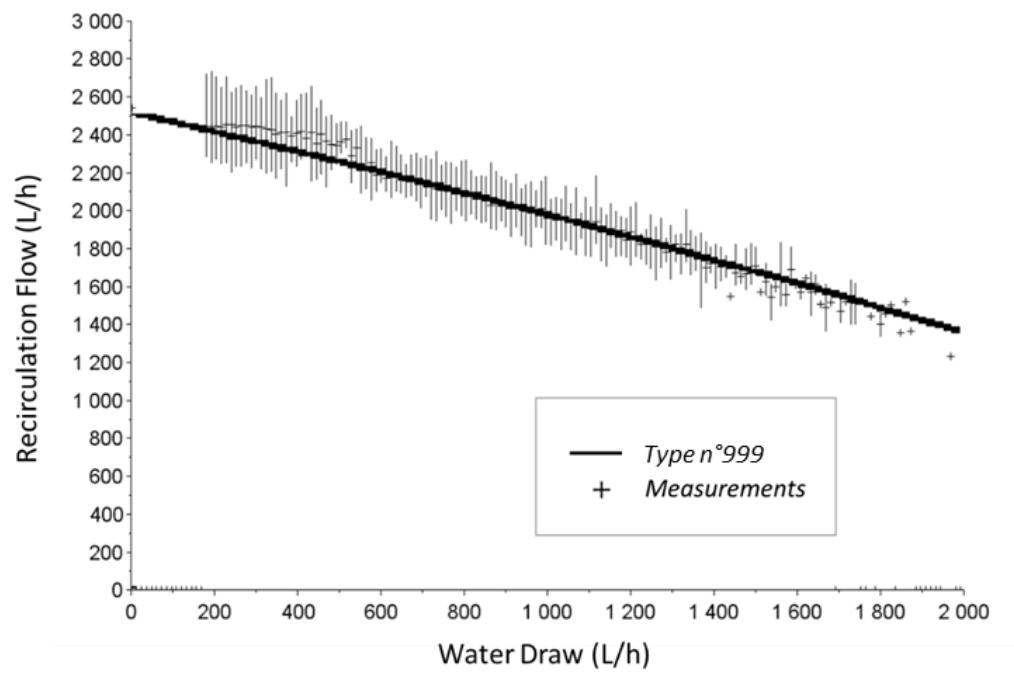

Figure 5 - Mean recirculation flow dependency to water draw obtained from the experiment (crosses with vertical lines representing maximal and minimal values) and from the new Type with singular pressure losses

The Type $\mathrm{n}^{\circ} 999$ parameters are then adapted to the real DHW installation: pump characteristics are approximated from manufacturer datasheet and geometric properties of the recirculation pipes are used to determine regular pressure drops. Singular pressure drops are limited to mixing device characteristic for $65 \mathrm{~mm}$ nominal flow diameter (THERMADOR, 2017). As only mixing valve pressure drops were known an equivalent is achieved by replacing these singular pressure drops by increased regular pressure drops.

The total pressure singular drop is the sum of each singular pressure drop ((Recknagel et al., 2005)) and can be expressed as:

$$
\Delta P_{\text {sing }}=\left(\sum \zeta_{u}\right) \frac{\rho}{2} v^{2} \quad(\mathrm{Eq} 10)
$$

With $\zeta_{u}$ being the singular pressure drop coefficient, $\rho$ the water density and $v$ the fluid speed. Each hydraulic component has a certain coefficient reflecting its effect on fluid pressure. An easier way to apprehend it is possible by computing an equivalent pipe length:

$$
l_{e q}=\left(\sum \zeta_{u}\right) \frac{D}{f}
$$

It gives the length of straight pipes that would generate the same regular pressure drop as what is caused by singular effects. The TRNSYS recirculation flow simulations computing the recirculation flow for different water draws show that the model closely approximates the real system (Figure 5) when an equivalent pipe length of 245 $\mathrm{m}$ is added to represent singular drops. The actual pipe length with regular drops is $300 \mathrm{~m}$ which means that the singular drops account for $45 \%$ of the total pressure drop for this installation. This value is consistent with a usual rule for hydraulic system design assuming 50\% of pressure drops from singularities (Recknagel et al., 2005). The experiment confirms the predicted decrease on recirculation flow when the user load is increased as shown in Figure 5. The lack of data for small draws (under $200 \mathrm{~L} / \mathrm{h}$ ) is caused by a fluid velocity under the minimal measurement threshold of $0.01 \mathrm{~m} / \mathrm{s}$.

Moreover, the experimentation lets us follow the mixing valve control with 10 seconds time step. A focus on 90 minutes is represented in Figure 6. It shows that, as expected, the mixing device takes more water from the tanks when there is a draw-off. It is caused by the temperature decrease at the valve cold entrance due to the arrival of cold water. However, these measurements are not adequate for a mixing valve dynamics study as the draw-off flow rate fluctuates quickly. A calibrated step response with a dedicated setup including temperatures inside the flows is necessary to evaluate mixing device time response. That was not the case during the observation period in the field. Moreover, it confirms that the accuracy of DHW consumption profile described earlier is limited by the 1 minute time resolution when considering quick draw offs that often last less than 20 seconds. 


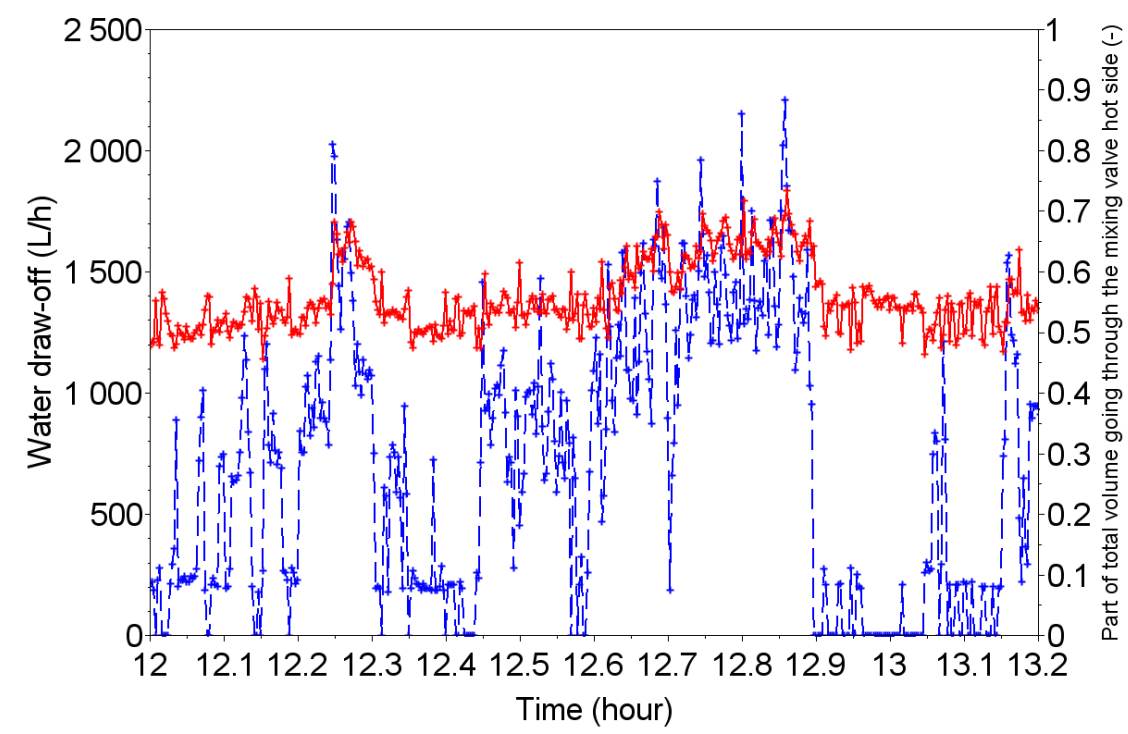

Figure 6 - Experimental mixing valve response (red - full line) to water draw-off (blue - dashed line)

\subsection{Reference System Model}

The reference SDHW system is described in the introduction and presented with TRNSYS models in Figure 7. The solar loop connects the $30 \mathrm{~m}^{2}$ glazed flat-plate collector field to an external heat exchanger with a $40 \mathrm{~L} / \mathrm{h} . \mathrm{m}^{2}$ flow rate. The solar tank volume is the same as the DHW average daily consumption which leads to $66 \mathrm{~L} / \mathrm{m}^{2}$ specific consumption ratio per solar collector area. A second tank of smaller volume is used for the auxiliary heating with a gas-fired boiler. A mixing valve ensures a $55^{\circ} \mathrm{C}$ temperature at the inlet of the distribution pipes, required by French regulation (Arrêté du 30 novembre 2005 modifiant l'arrêté du 23 juin 1978 relatif aux installations fixes destinées au chauffage et à l'alimentation en eau chaude sanitaire des bâtiments d'habitation, des locaux de travail ou des locaux recevant du public, n.d.). The recirculation loop is designed to meet the rules described in (AFNOR, 2013).

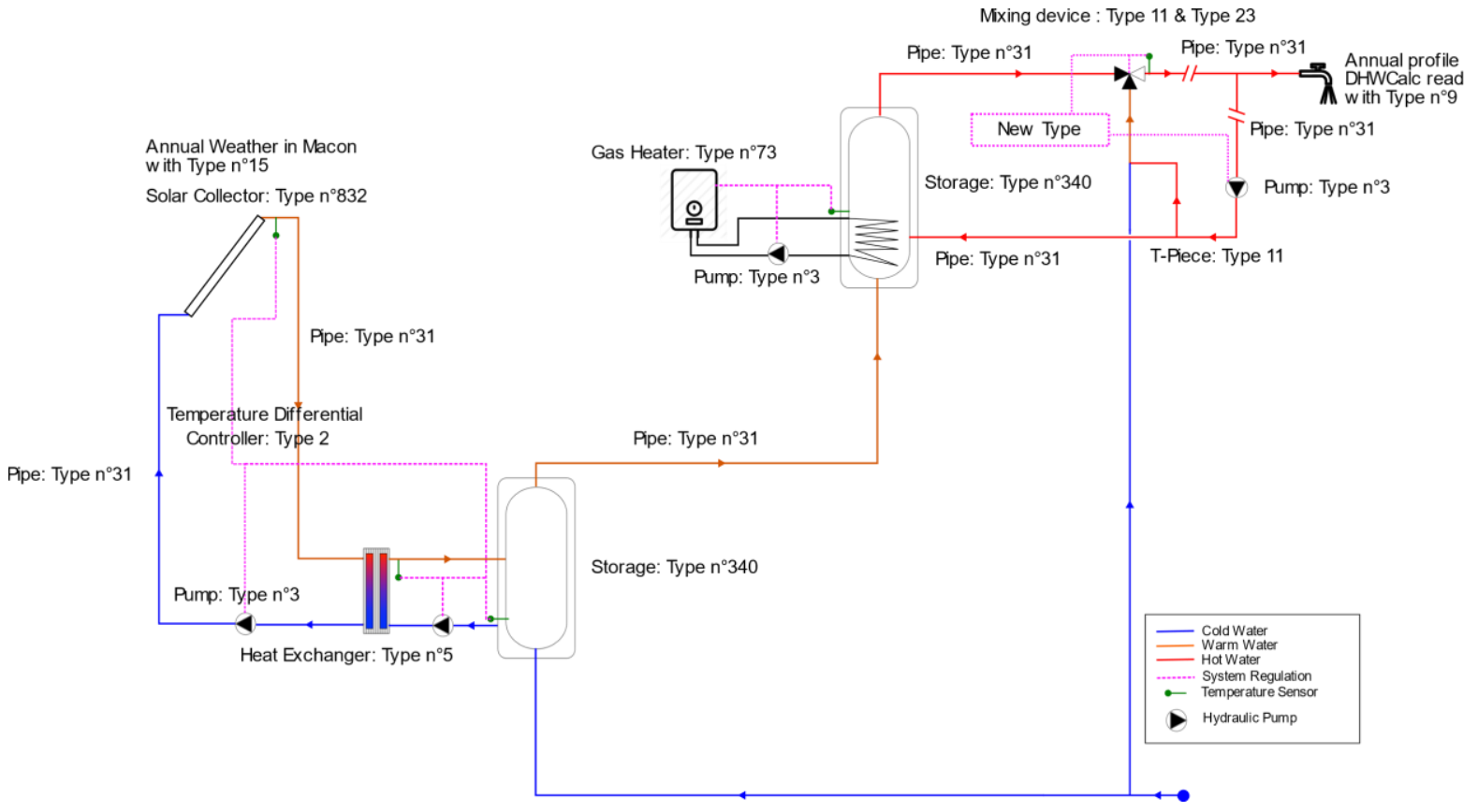

Figure 7 - Hydraulic system model on TRNSYS

The dynamic simulation software TRNSYS is used to model this system (Shrivastava et al., 2017). Each 
component is modeled separately in a "Type" in Fortran or C++ programming languages.

As shown in Figure 7, several native Types are applied: pipes (Type 31), hydraulic pump (Type 3), differential temperature controllers (Type 2), counter flow heat exchanger (Type 5)... Non-native Types are necessary for major components: solar collector (Type 832), storage tank (Type 340) and boiler (Type 73). Storage is modeled as a multi-node tank with several isothermal layers, which has been found in good agreement with experimentation (Dickinson et al., 2013). In this reference case, parametric analysis shows that 60 nodes for the solar tank and 10 nodes for the auxiliary tank provide the model with a good accuracy (difference with solar energy recovered in the collector lower than $0.2 \%$ ). This is represented for the solar tank in Figure 8.

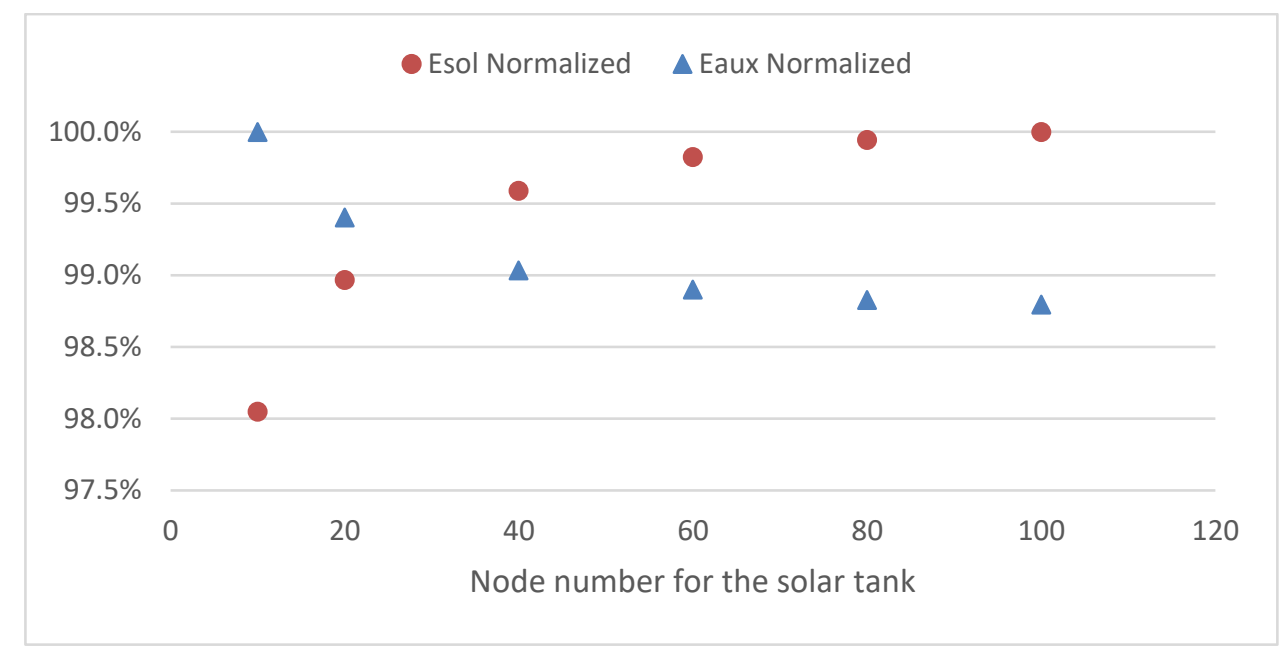

Figure 8 - Normalized recovered solar energy at the collector (Esol) and delivered energy by auxiliary heating (Eaux) for different node numbers of solar tank model and with 10 nodes for the auxiliary tank

Parameter configuration of these main components is detailed in Table 2 :

\begin{tabular}{|c|c|c|c|}
\hline Component & Parameter & Value & Unit \\
\hline \multirow[t]{6}{*}{ Solar Loop } & Solar Collector Surface & 30 & $\mathrm{~m}^{2}$ \\
\hline & Primary Loop Flow Rate & 1200 & $\mathrm{~L} / \mathrm{h}$ \\
\hline & Total Pipe Length & 24 & $\mathrm{~m}$ \\
\hline & Pipe Diameter & 0.03 & $\mathrm{~m}$ \\
\hline & $\begin{array}{l}\text { Threshold Temperature } \\
\text { Difference for Activation }\end{array}$ & 5 & ${ }^{\circ} \mathrm{C}$ \\
\hline & $\begin{array}{l}\text { Threshold Temperature } \\
\text { Difference for turning } \\
\text { down }\end{array}$ & 1 & ${ }^{\circ} \mathrm{C}$ \\
\hline \multirow[t]{5}{*}{ Solar Storage } & Solar Tank Volume & 2000 & $\mathrm{~L}$ \\
\hline & Solar Tank Height & 2.4 & $\mathrm{~m}$ \\
\hline & $\begin{array}{l}\text { External Heat Exchanger } \\
\text { Capacity }\end{array}$ & 5400 & $\mathrm{~kJ} / \mathrm{h} .{ }^{\circ} \mathrm{C}$ \\
\hline & $\begin{array}{l}\text { Secondary Loop Flow } \\
\text { Rate }\end{array}$ & 1200 & $\mathrm{~L} / \mathrm{h}$ \\
\hline & $\begin{array}{l}\text { Solar Heated Water } \\
\text { Injection Relative Height }\end{array}$ & 0.33 & - \\
\hline
\end{tabular}




\begin{tabular}{|c|c|c|c|}
\hline \multirow[t]{8}{*}{ Auxiliary Storage } & Auxiliary Tank Volume & 300 & $\mathrm{~L}$ \\
\hline & Auxiliary Tank Height & 1.2 & $\mathrm{~m}$ \\
\hline & $\begin{array}{l}\text { Gas-Fired Boiler Nominal } \\
\text { Power }\end{array}$ & 60 & $\mathrm{~kW}$ \\
\hline & $\begin{array}{l}\text { Internal Heat Exchanger } \\
\text { Capacity }\end{array}$ & 3120 & $\mathrm{~kJ} / \mathrm{h} .{ }^{\circ} \mathrm{C}$ \\
\hline & $\begin{array}{l}\text { Internal Heat Exchanger } \\
\text { Relative Height }\end{array}$ & 0.3 & - \\
\hline & $\begin{array}{l}\text { Returned Hot Water } \\
\text { Injection Relative Height }\end{array}$ & 0.2 & - \\
\hline & $\begin{array}{l}\text { Auxiliary Set Point } \\
\text { Temperature }\end{array}$ & 60 & ${ }^{\circ} \mathrm{C}$ \\
\hline & $\begin{array}{l}\text { Threshold Temperature } \\
\text { Difference for Activation }\end{array}$ & 4 & ${ }^{\circ} \mathrm{C}$ \\
\hline \multirow[t]{2}{*}{ Mixing Device } & $\begin{array}{l}\text { Output Set Point } \\
\text { Temperature }\end{array}$ & 55 & ${ }^{\circ} \mathrm{C}$ \\
\hline & $\begin{array}{l}\text { Response Time }(5 \% \text { of } \\
\text { final value for an } 600 \mathrm{~L} / \mathrm{h} \\
\text { water draw) }\end{array}$ & 1 & $\min$ \\
\hline \multirow[t]{5}{*}{ Recirculation Loop } & $\begin{array}{l}\text { Upstream user draw pipe } \\
\text { length }\end{array}$ & 110 & $\mathrm{~m}$ \\
\hline & $\begin{array}{l}\text { Upstream user draw pipe } \\
\text { diameter }\end{array}$ & 0.03 & $\mathrm{~m}$ \\
\hline & Return Pipe Length & 110 & $\mathrm{~m}$ \\
\hline & Return Pipe Diameter & 0.02 & $\mathrm{~m}$ \\
\hline & $\begin{array}{l}\text { Nominal Recirculation } \\
\text { Flow Rate }\end{array}$ & 500 & $\mathrm{~L} / \mathrm{h}$ \\
\hline \multirow[t]{3}{*}{ Other } & Location & Mâcon, France & - \\
\hline & Mean Daily Draw at $45^{\circ} \mathrm{C}$ & 2000 & L/day \\
\hline & $\begin{array}{l}\text { Incoming Cold Water } \\
\text { Temperature }\end{array}$ & Around $15^{\circ} \mathrm{C}$ & - \\
\hline
\end{tabular}

Table 2 - Main components parameter configuration of the reference system

A statistically built draw-off profile (from DHWCalc (Jordan and Vajen, 2001a)) is used to approximate real consumption variations for multi-family buildings. Realistic consumption profiles are irregular and depend on multiple factors that are not considered in "DHWCalc" (Lomet et al., 2015). Yet, there are significant differences between fixed consumption pattern (as in EN 12977 Standards (AFNOR, 2018)) and DHW profiles based on field measurements, like "DHWCalc" (Spur et al., 2006). Therefore, it was selected for this work as a more useful approximation of realistic profiles than typical daily draw-off profile from Standards.

Reference profiles are often used in simulations ((Geoghegan and Lior, 1984), (Zainine et al., 2017)). Realistic profiles cause a performance loss compared to usual reference profile ( 3 draw-off per day...) (Jordan and Vajen, 2001b; Knudsen, 2002). A 5 minute DHW consumption model has been developed by (Edwards et al., 2015) and has shown that it significantly impacts model results.

A statistically built hot water profile from (Jordan and Vajen, 2001a) has been used in this work as it allows to model dynamic phenomenon. It takes into account four categories of load: small, medium, shower and bath. Each 
of them has different mean flow rate, duration and daily occurrences. A statistical deviation from these values is added and probability variations appear on a daily, weekly and monthly basis. The one-minute profile is generated for a 20 apartments building consuming a total of $2000 \mathrm{~L} /$ day at $45^{\circ} \mathrm{C}$. This is a usual demand in France for multifamily buildings (ADEME, 2018). Daily consumption is shown in Figure 9. Each family takes a two weeks holiday randomly in July and August, which explains the major decrease in draw-off volume during these two months. The absence periods need to be considered because it can lead to overheating which would damage the system. Figure 9 also displays the seasonal load evolution modeled as a sinus with a maximum in February. It reflects the user's DHW consumption decrease in summer. It must be noted that realistic consumption profiles are irregular and depend on multiple factors that are not taken into account by "DHWCalc" (Lomet et al., 2015).

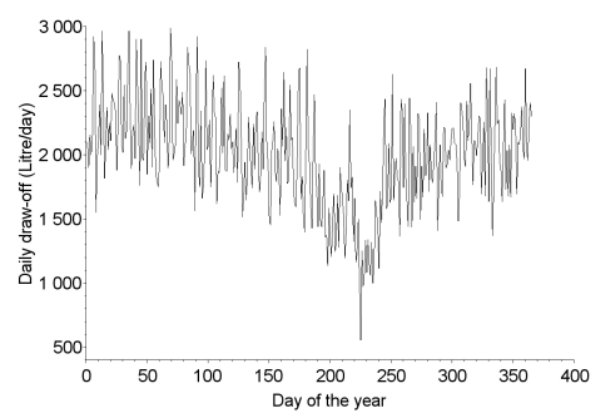

Figure 9 - DHW daily load

The reference system developed in this study has a mean temperature delivery of $53^{\circ} \mathrm{C}$ (at end-user draw-off level). Thus, the draw-off volume from DHWCalc is adapted to deliver the same energy to the user as it was expected at a $45^{\circ} \mathrm{C}$ temperature:

$$
Q_{D H W}=Q_{D H W C a l c} \frac{\left(45-T_{\text {cold }-D H W C a l c}\right)}{\left(53-T_{\text {cold }- \text { mean }}\right)}
$$

With $T_{\text {cold-mean }}=12.1^{\circ} \mathrm{C}$, mean cold water temperature in the selected weather file (Macon in the east of France) and $T_{\text {cold-DHWCalc }}=10{ }^{\circ} \mathrm{C}$, default cold water temperature in DHWCalc. The instantaneous cold water temperature is used in the model for the incoming water during draw-off. In this way, the energy needed to heat a certain volume of water in summer is lower than in winter because the cold water is initially hotter. The whole model is built as the assembly of the two newly developed models and standard Types.

All standard TRNSYS types have been validated individually in the past. Thus, the global validation of the simulation is focused on the verification of the following energy balance:

$$
\begin{gathered}
\int_{0}^{8760}\left(P_{\text {sol }}+P_{\text {aux }}+\varepsilon P_{\text {elec }}\right) d t=\int_{0}^{8760}\left(P_{D H W}+P_{\text {Loss-Sol }}+P_{\text {Loss-Stosol }}+P_{\text {Loss-StoAux }}+P_{\text {Loss }-D H W}\right) d t+ \\
\Delta E_{\text {Sto }}+\delta \quad(\text { Eq 13) }
\end{gathered}
$$

With, as inputs:

- $\quad P_{\text {sol }}=\frac{Q_{\text {sol } \rho c_{p-c a l o}\left(T_{c-o u t}-T_{c-i n}\right)}}{3,6 \times 10^{6}}:$ Recovered solar heat

- $P_{a u x}$ : Power delivered by the auxiliary system (gas-fired boiler here)

- $\varepsilon P_{\text {elec }}$ : Share of the pump's electrical power consumption converted into thermal power given to the fluid $(\varepsilon=5 \%)$

Outputs:

- $\quad P_{D H W}=\frac{Q_{D r a w} \rho c_{p-D H W}\left(T_{D H W}-T_{c o l d}\right)}{3,6 \times 10^{6}}:$ Power delivered to the user

- $\quad P_{\text {Loss }-S o l}:$ Heat loss in solar loop

- $P_{\text {Loss-Stosol }}$ : Heat loss in solar tank

- $P_{\text {Loss-StoAux }}:$ Heat loss in auxiliary tank

- $P_{\text {Loss-DHW }}$ : Heat loss in recirculation loop 
And $\Delta E_{\text {sto }}$ the internal energy change and $\delta$ the error. The simulations gave us energy balance errors near $0.005 \%$ of the total input energy in the system. It is in the same order of magnitude as the tolerance criterion taken for this model: 0.0001 .

\subsection{Multiple performance criteria}

Previous literature mostly considered the energetic performances of the system with different indicators such as the fractional energy savings ((Jordan and Vajen, 2001b)) or solar fraction ((Hobbi and Siddiqui, 2009)). Yet numerous other indicators are significant when looking at system performances. Moreover, as emphasized in the introduction, the solar DHW installations are facing several challenges to strengthen their market position. Therefore this work introduced several criteria to rate the installation configurations with regard to these challenges, as listed in Table 3.

The main energy criteria considered in this work is the fractional energy savings. It is computed as:

$$
f s a v=\frac{C_{E P, G a s}-C_{E P}}{C_{E P, G a s}}
$$

With $\left(C_{E P}\right)$ being the gross energy consumption of the studied system and $\left(C_{E P, G a s}\right)$ the gross energy consumption of gas-only system, represented in Figure 10, with the same sizing and loads. It is noticeable that this criteria includes recirculation heat losses which are significant in multi-family buildings. This criterion applies at whole system scale. Economic savings and $\mathrm{CO}_{2}$ emission are deriving directly from $f s a v$ but they are not the focus of this work.

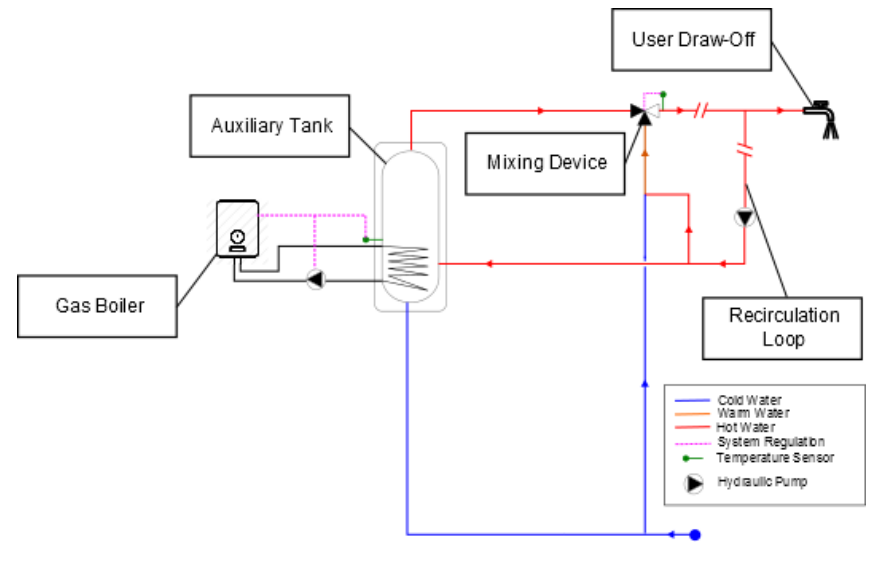

Figure 10 - Gas-only system design

In addition, regulation compliance is highly relevant for these systems. The main rule concerns temperature in the recirculation loop. It has to remain warmer than $50^{\circ} \mathrm{C}$ everywhere in the pipes, otherwise it favors legionella development (AFNOR, 2013). The coldest point is located at the end of the return pipe. Fluid temperature at this point is monitored in the following simulations.

In order to analyze the user demand fulfillment, a comfort criterion is computed as the cumulated time period during which the delivery draw-off temperature goes under $45^{\circ} \mathrm{C}$. This temperature is necessary for usual DHW use.

Lastly, since the durability of the system components is also to be preserved, relevant performance indicators are proposed: for instance, a well-performing system minimizes the number of valve cycles per year or prevents overheating in the collector and solar tank.

\begin{tabular}{|c|c|}
\hline DOMAIN & CRITERIA \\
\hline Energy & $\begin{array}{l}\text { - Fractional Energy Savings: } \boldsymbol{f} \boldsymbol{s a v}=\frac{\boldsymbol{C}_{E P, G a s}-C_{E P}}{C_{E P, G a s}} \\
\text { - } \\
\text { Solar Fraction: } F S=\frac{E_{S o l}}{E_{D H W}} \text { with } E_{S o l} \text { the recovered solar energy at } \\
\text { the collector and } E_{D H W} \text { the energy delivered to the user } \\
\text { - Collector mean efficiency: } \eta=\frac{E_{S o l}}{E_{\text {Radiation }}} \text { with } E_{\text {Radiation }} \text { the solar } \\
\text { energy arriving on the collector surface }\end{array}$ \\
\hline
\end{tabular}




\begin{tabular}{|c|c|}
\hline Regulation & $\begin{array}{l}\text { - Percentage of the time when recirculation return loop } \\
\text { temperature is below regulation requirement }\left(50^{\circ} \mathrm{C}\right) \\
\text { - } \\
\text { (riticality criterion for cold plug flows in the recirculation loop } \\
\sum_{\text {allplugFlows }}\left(\Delta t_{p l u g} \times \Delta T_{p l u g}\right) \text { with } R_{p l u g} \text { the criticality } \\
\text { criterion in }{ }^{\circ}{ }^{\circ} \mathrm{C}, \Delta t_{\text {plug }} \text { the cold plug flow duration (h) and } \\
\Delta T_{\text {plug }} \text { the maximal deviation below } 50^{\circ} \mathrm{C}\left({ }^{\circ} \mathrm{C}\right)\end{array}$ \\
\hline Component Durability & 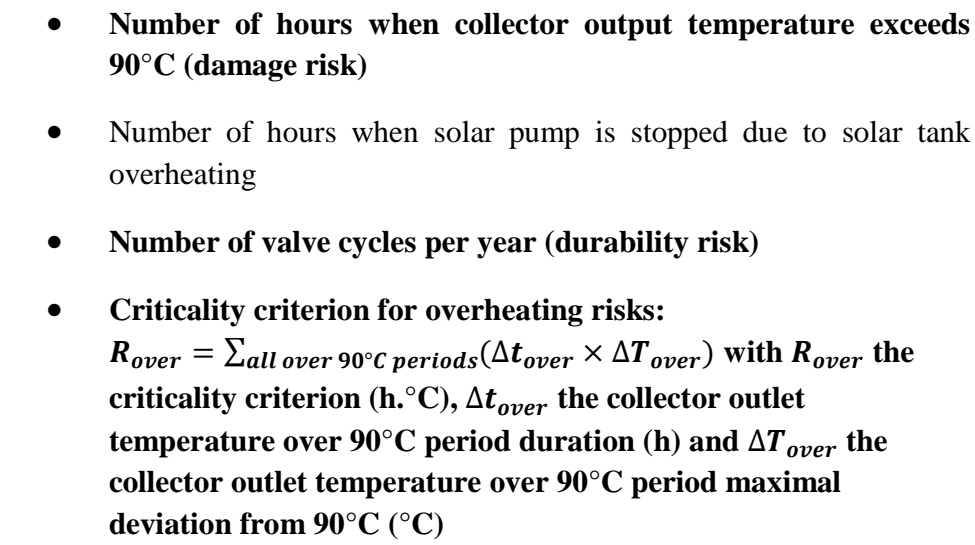 \\
\hline User Comfort & $\begin{array}{l}\text { Percentage of the draw off time when DHW delivery temperature is below } \\
\qquad 45^{\circ} \mathrm{C} \text {. }\end{array}$ \\
\hline
\end{tabular}

Table 3 - Multiple criteria followed during this work

\section{Simulation results and discussion}

As explained in the introduction, solar thermal technology faces competitiveness issues compared to other technologies for DHW heating market. Competitivity does not only refers to energy efficiency, but also to regulation compliance or components durability as it can strongly impact system profitability. Starting first from the reference system model presented in above sections, this work analyses the influence of system characteristics on the system performance with regard to multiple criteria. In a second time, the analysis focuses on the multicriteria performance of a system with a recirculation loop connection to the solar tank, as a path to competiveness improvement.

Parametric studies are performed with JEPlus tool which generates input file for each parameter value and launches TRNSYS calculation sequentially (“JEPlus Website," n.d.). Table 4 summarizes all annual major simulations showing the impact of mixing valve and solar recirculation loop on system key performance indicators. The simulations are named after their main characteristic or modification compared to reference.

\begin{tabular}{|c|c|c|c|c|c|c|c|c|c|}
\hline \multirow{2}{*}{$\begin{array}{l}\text { Simulation } \\
\quad \text { Ref }\end{array}$} & \multirow{2}{*}{$\begin{array}{l}\text { With } \\
\text { Recirculation } \\
\text { Loop? }\end{array}$} & \multirow{2}{*}{$\begin{array}{c}\text { Parameter } \\
\text { modifications }\end{array}$} & \multirow{2}{*}{ Performance criteria } & \multicolumn{6}{|c|}{ Influence of mixing valve $95 \%$ response time } \\
\hline & & & & $10 \mathrm{~min}$ & $6 \mathrm{~min}$ & $2 \mathrm{~min}$ & $1 \mathrm{~min}$ & $0.5 \mathrm{~min}$ & $0 \mathrm{~min}$ \\
\hline 1 - Energy & & & fsav & $27,7 \%$ & $27,8 \%$ & $28,2 \%$ & $28,5 \%$ & $28,7 \%$ & $29,1 \%$ \\
\hline 1 - Regulation & No & & $\begin{array}{l}\% \text { of the year spent under } \\
50^{\circ} \mathrm{C} \text { at the end of the } \\
\text { recirculation loop }\end{array}$ & $19,4 \%$ & $18,2 \%$ & $13,8 \%$ & $9,6 \%$ & $5,5 \%$ & $0,1 \%$ \\
\hline 2 - Energy & & & fsav & $24,3 \%$ & $24,4 \%$ & $25,0 \%$ & $25,4 \%$ & $25,7 \%$ & $26,2 \%$ \\
\hline 2 - Regulation & No & $\begin{array}{c}\text { point temperature } \\
\text { set at } 65^{\circ} \mathrm{C}\end{array}$ & $\begin{array}{l}\% \text { of the year spent under } \\
50^{\circ} \mathrm{C} \text { at the end of the } \\
\text { recirculation loop }\end{array}$ & $24,2 \%$ & $23,0 \%$ & $17,1 \%$ & $11,6 \%$ & $6,3 \%$ & $0,0 \%$ \\
\hline 3 - Energy & & & fsav & $25,2 \%$ & $25,4 \%$ & $25,9 \%$ & $26,3 \%$ & $26,7 \%$ & $27,2 \%$ \\
\hline 3 - Regulation & No & $\begin{array}{l}\text { recirculation flow } \\
\text { rate set at } 700 \mathrm{~L} / \mathrm{h}\end{array}$ & $\begin{array}{l}\% \text { of the year spent under } \\
50^{\circ} \mathrm{C} \text { at the end of the } \\
\text { recirculation loop }\end{array}$ & $13,8 \%$ & $12,7 \%$ & $9,2 \%$ & $5,9 \%$ & $3,4 \%$ & $0,0 \%$ \\
\hline 4 - Energy & No & $\begin{array}{c}\text { Auxiliary set- } \\
\text { point set at } 57^{\circ} \mathrm{C}\end{array}$ & fsav & $\mathrm{x}$ & $\mathrm{x}$ & $\mathrm{x}$ & $\mathrm{x}$ & $\mathrm{x}$ & $27,5 \%$ \\
\hline
\end{tabular}




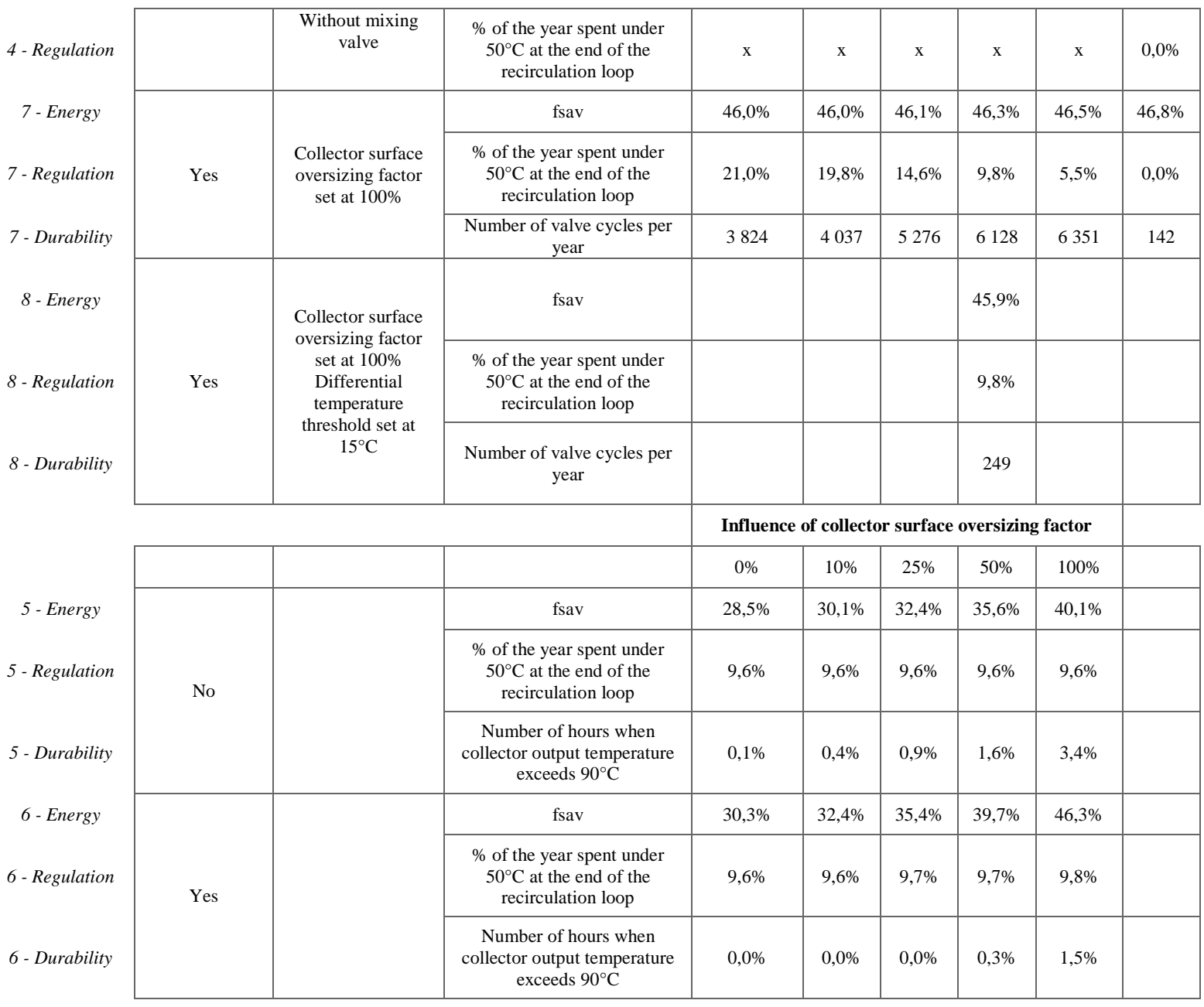

Table 4 - Key results summary from parametric study

\subsection{Reference system analysis}

\section{- 1-Annual Energy Performance of the reference system}

The mixing valve dynamic effect on energy performance is shown in Figure 11. For the reference system, about $3.5 \%$ of the fractional energy savings is lost between a fast mixing valve with 30 seconds response time and a slow one with 10 minutes. The reason is explained from the second curve on this figure: a slow mixing valve reduces the volume of cold water going inside the solar tank during draw-off. A larger part of it skips the storage and enters the cold entrance of the mixer. Thus, the potential solar energy recovery is limited because the energy drawn out of the storage is smaller, which explains the performance loss. 


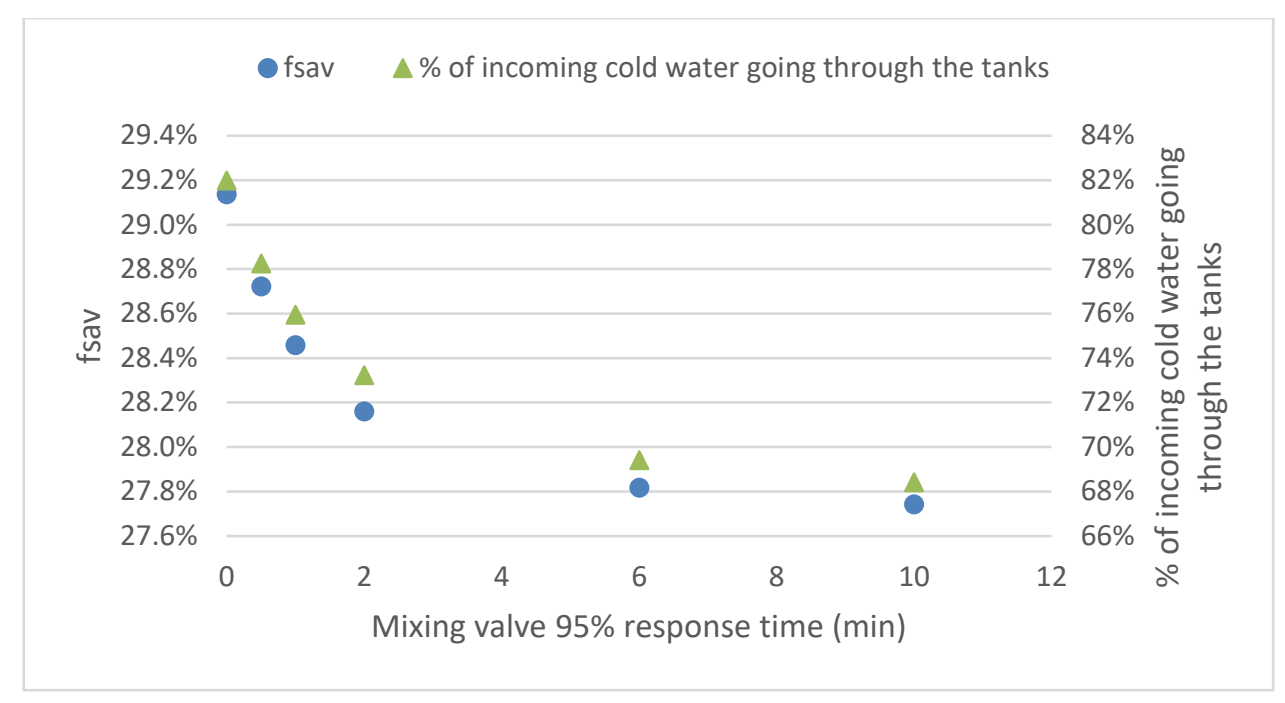

Figure 11 - Mixing valve response time influence on fractional energy savings and portion of cold water flowing through the tanks for DHW production

\section{- 2-hours window energy analysis of the reference system}

The explanation of the previous phenomenon is established with Figure 12. When there is no draw-off, the mixing valve position is mainly constant (except slow variations due to hot side temperature change caused by the temperature differential needed before auxiliary system starts heating). As soon as the draw-off occurs, cold water is injected in the system following the initial repartition of the mixer. Initially around $51^{\circ} \mathrm{C}$, which is the recirculation loop return water temperature, the cold side temperature at the mixing device drops because of water injection with a mean temperature of $12^{\circ} \mathrm{C}$. The mixer needs to send a greater volume of hot water to ensure a constant temperature at its output. For a duration corresponding to mixer response time, cold water skips the tanks.
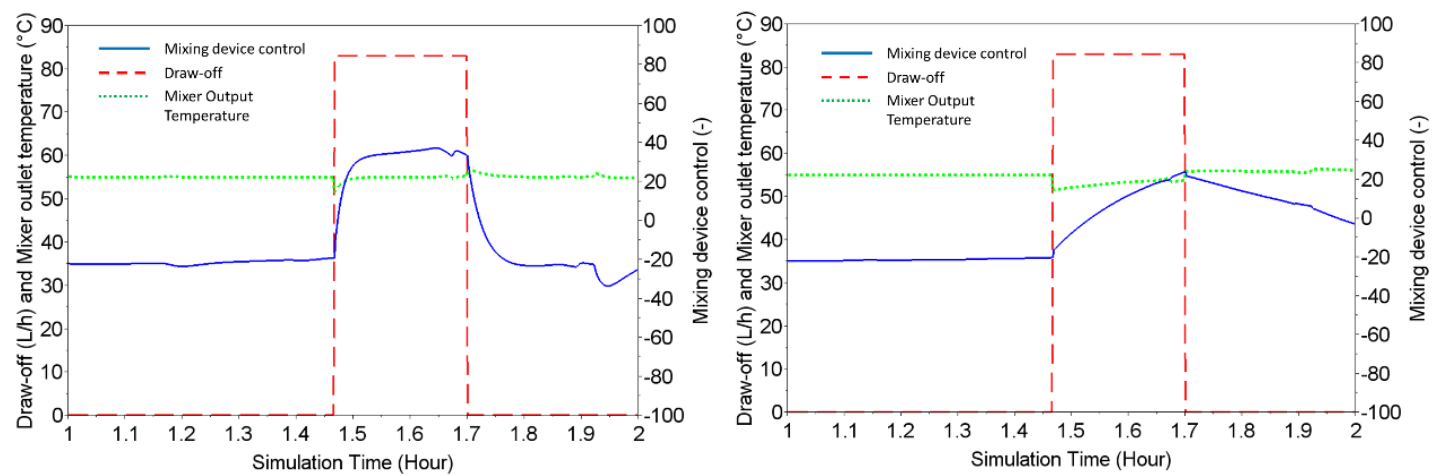

Figure 12 - Mixing valve control (blue - full line, 100: all hot side, -100: all cold side) and mixing device outlet temperature (green - dotted line) with a response time of $1 \mathrm{~min}$ (left) and $10 \mathrm{~min}$ (right) during a draw-off (red - dashed line)

\section{- 1 - Annual Regulation Performance for the reference system}

The consequences are not only reduced energy performance: during transient time, the mixer temperature output is under the setpoint temperature $55^{\circ} \mathrm{C}$. With heat losses in the recirculation loop, it leads to a minimal water temperature below $50^{\circ} \mathrm{C}$, which is prohibited by the French regulation (AFNOR, 2013) and increases the risk of legionella growth. The time spent under $50^{\circ} \mathrm{C}$ at the end of the recirculation loop for different mixer response times is listed in Table 5. It means that for usual mixing valve, with response time around 1 minute, the minimal loop temperature is under $50^{\circ} \mathrm{C}$ during more than 800 hours.

\begin{tabular}{|c|c|c|c|c|c|c|}
\hline Mixer response time $(\mathbf{m i n})$ & $\mathbf{1 0}$ & $\mathbf{6}$ & $\mathbf{2}$ & $\mathbf{1}$ & $\mathbf{0 . 5}$ & $\mathbf{0}$ \\
\hline $\begin{array}{c}\text { \% of the year spent under } 50^{\circ} \mathrm{C} \\
\text { at the end of the recirculation } \\
\text { loop }\end{array}$ & $19.4 \%$ & $18.2 \%$ & $13.8 \%$ & $9.6 \%$ & $5.5 \%$ & $0.1 \%$ \\
\hline
\end{tabular}


Table 5 - Portion of the year spent under $50^{\circ} \mathrm{C}$ at the end of the recirculation loop for different response times

The mixing device generates cold water plug flows inside the recirculation loop. The criticality of these can be assessed by two aspects: its duration and its maximal gap under $50^{\circ} \mathrm{C}$. The results, visible in Figure 13 and processed with Scilab software ("Home Page | www.scilab.org," n.d.), show the impact of mixer response time and draw-off durations. The left figure indicates that all plug flows have a duration under 30 seconds which is the mixer response time. It is understandable that the cold plug flow durations cannot be greater than the response time because the error is zero after that. The amplitude reaches $10^{\circ} \mathrm{C}$, which means that the minimal temperature is $40^{\circ} \mathrm{C}$ at the end of the recirculation loop.

The right figure shows that the main part of the cold plug flows lasts around 1 minute, despite the fact that the response time is 10 minutes. This is caused by the previously introduced draw-off profile that was used in these simulations. Indeed, the majority of the loads are small and medium draw-offs, with a mean duration of 1 minute. In these cases, the mixer does not have enough time to reach the needed repartition and the cold plug flow lasts for the entire load duration. However, there are still 8 to 10 minutes cycles under $50^{\circ} \mathrm{C}$, which appear during long draw-offs. These are the most critical regarding the legionella growth risk. Indeed, a criticality criterion showing the risks caused by these cold plug flows can be computed. This criterion is defined in multiple criteria Table 3 .

The criticality is about $2022 \mathrm{~h} .{ }^{\circ} \mathrm{C}$ with a 30 seconds response time while it reaches $6124 \mathrm{~h} .{ }^{\circ} \mathrm{C}$ with 10 minutes. The legionella risk is thus extended by $300 \%$. It must be noted that the DHW distribution network is simplified. In real systems, there would be stagnant branches or derivations that would amplify these cold plug flows and thus the legionella growth risks.

It is thus needed to ensure that the mixing valve used is regularly maintained to minimize these risks.
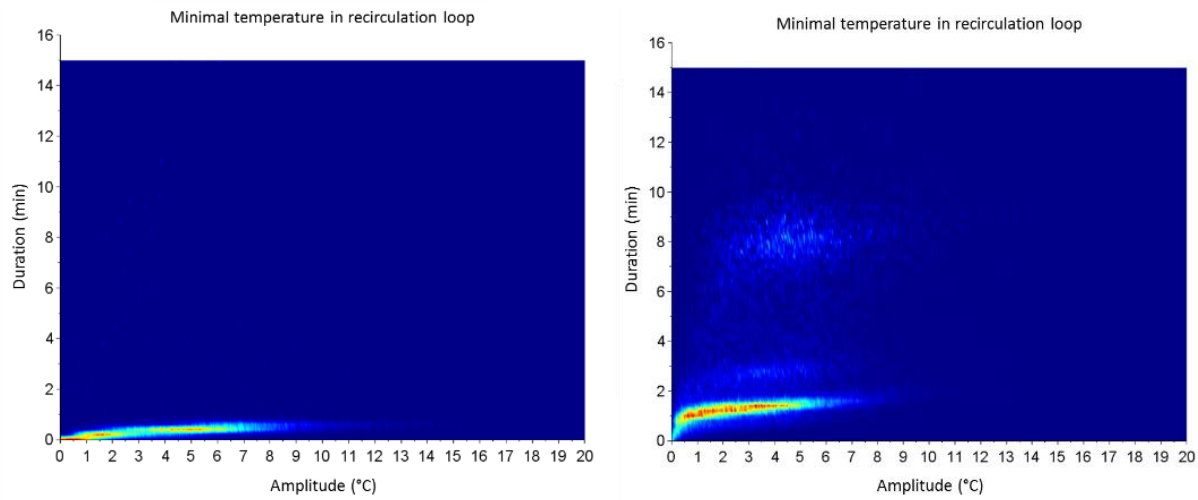

Figure 13 - Cold water plug flow repartition in duration and maximal deviation below $50^{\circ} \mathrm{C}$ for mixer time response of $0.5 \mathrm{~min}$ (left) and $10 \mathrm{~min}$ (right)

\section{- 2-Annual Energy and Regulation performance with auxiliary set-point temperature set at $65^{\circ} \mathrm{C}$}

The section focuses the study on the effects of a few changes in system architecture and control. First of all, the auxiliary set-point temperature, initially at $60^{\circ} \mathrm{C}$, is increased by $5^{\circ} \mathrm{C}$. The consequence is fractional energy savings decrease by $10 \%$. This is due to the warmer fluid at the hot input of the mixer, which causes more cold water directly to the cold water entrance, skipping the solar tank. Moreover, the cold plug flows generated by the mixing valve have greater amplitude that can reach $15^{\circ} \mathrm{C}$. As a result, auxiliary set-point temperature should be minimized.

With the reference system settings defined in Table 2 , the temperature in the auxiliary tank varies between $56^{\circ} \mathrm{C}$ and $60^{\circ} \mathrm{C}$, because the required temperature difference for auxiliary to start is $4^{\circ} \mathrm{C}$. Considering increased setpoint at $65^{\circ} \mathrm{C}$ leads to temperature variations between $61^{\circ} \mathrm{C}$ and $65^{\circ} \mathrm{C}$ which means increased heat storage loss and a larger cold water volume skipping the solar tank. An option to limit its detrimental effects on performance is to increase the differential temperature set-point to $10^{\circ} \mathrm{C}$, in order to let the temperature vary between $65^{\circ} \mathrm{C}$ and $55^{\circ} \mathrm{C}$. However, the performance loss is still of $7 \%$, because of thermal stratification inside the auxiliary tank. The temperature at mixer hot entrance is often hotter than near the temperature sensor controlling auxiliary heating. 


\section{- 3- Annual Energy and Regulation performance with nominal recirculation flow rate set at $700 \mathrm{~L} / \mathrm{h}$}

A similar loss in energy savings is observed when the recirculation pump is oversized. Indeed the greater return flow rate leads to a hotter fluid at the end of the return pipe. It helps reducing the time spent under $50^{\circ} \mathrm{C}$ but the increased mixer cold entrance temperature requires a larger volume of cold water skipping the tanks.

\section{- 4-Annual Energy and Regulation performance without mixing valve and auxiliary set point temperature set at $57^{\circ} \mathrm{C}$}

Removing the mixing valve can be acceptable for the reference system if the set-point auxiliary temperature is reduced. Indeed, the energy savings factor reaches $27.5 \%$ with $57^{\circ} \mathrm{C}$ as set-point and it has the benefit to virtually eliminate temperature occurrences under $50^{\circ} \mathrm{C}$ at the recirculation loop end. However, high temperature are sometimes delivered to the user, which may cause scalding. Therefore, this solution cannot be considered.

\subsection{Solar recirculation loop system analysis}

\section{- $\quad 5$ \& 6- Annual Energy performance with and without solar recirculation loop}

In this work, the returned water, at about $51{ }^{\circ} \mathrm{C}$, is sent to the solar storage if its top water is $4{ }^{\circ} \mathrm{C}$ warmer. The new architecture is represented in Figure 14. The 3 -way valve is modeled by a linear time response with a 30 seconds duration to change between the positions of the two extrema.

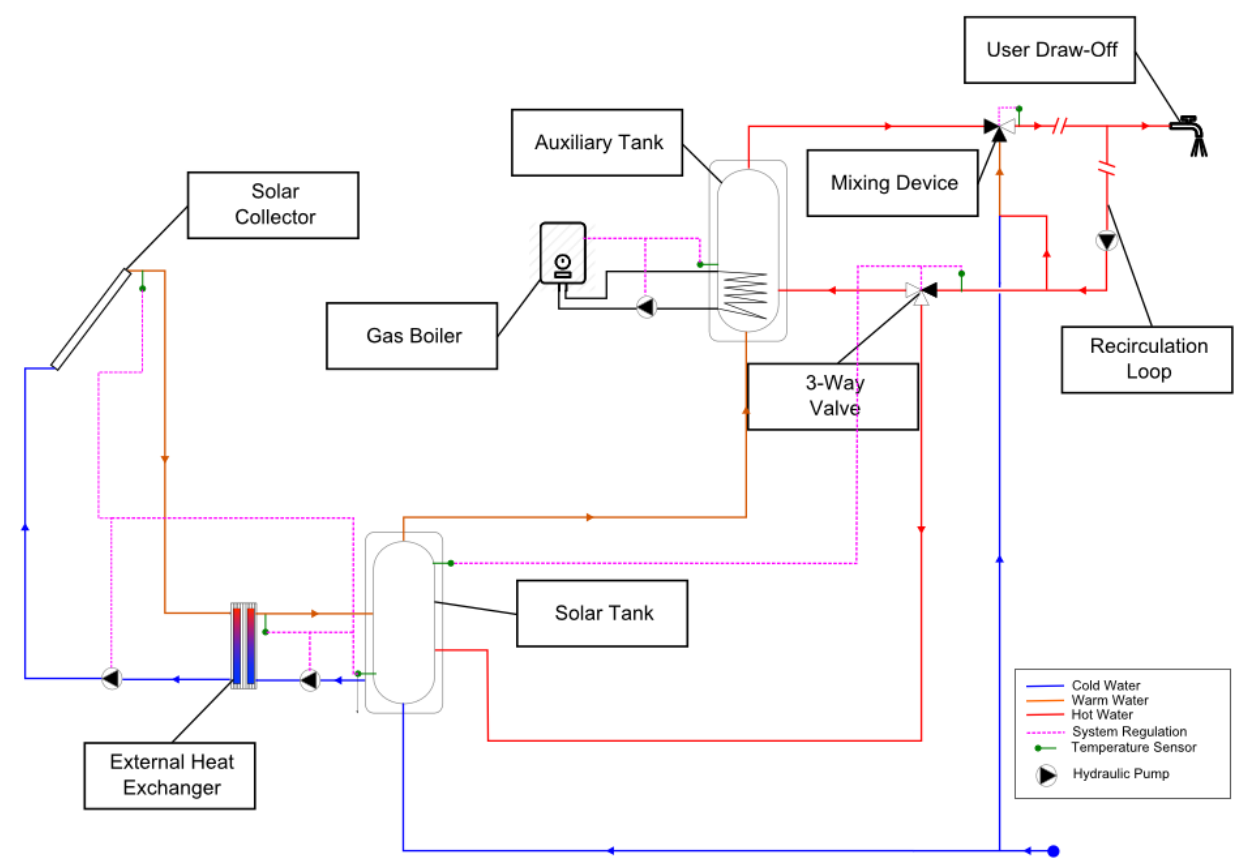

Figure 14 - System architecture and sizing with the linking of the recirculation loop to the solar tank

This recirculation link to solar tank is added to the reference case. It leads to an increase in fractional energy savings from $28.5 \%$ to $30.3 \%$. This is caused by solar tank cooling when recirculation return water is sent to it, which represents $11 \%$ of the annual volume. A greater energy is thus retrieved from the solar loop. The recirculation connection to the solar tank fulfills its goals. However, the limited gain in energy performance and the low overheating risk with the reference sizing rules in the reference system case don't justify the added complexity and malfunction risk.

When solar production is oversized compared to the load, this solution may become attractive. In this work, the collector surface is increased for this purpose with constant tank volume and DHW demand. By reciprocity, we assume that the effects are similar with reduced DHW demand and constant solar collector size. It may happen during the system lifetime due to behavior change or user moves. The effect of oversizing is shown in Figure 15. Obviously, the savings are higher when the collector surface is increased, because more solar energy is recovered. 
The growing gap between the two curves means that the recirculation loop linking to solar tank leads to better gain when the solar production is oversized or when the demand is reduced. The fsav increase with $60 \mathrm{~m}^{2}$ of solar collectors is $15 \%$ versus $6 \%$ in the reference case.

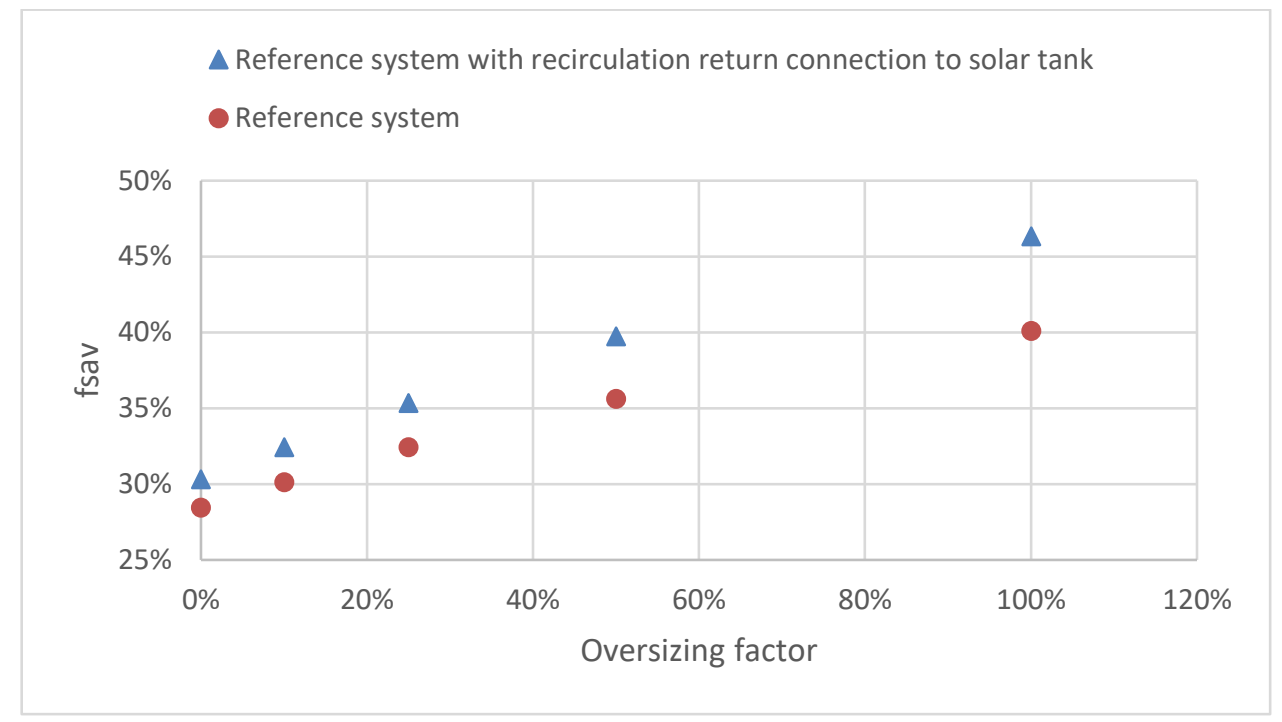

Figure 15 - Fractional energy savings for different collector sizing, with (triangle - blue) and without (circle - red) recirculation loop link to solar tank

- 5 \& 6 - Annual Durability performance with and without solar recirculation loop

One drawback of this oversizing, often considered as a prohibitive factor, is the greater risk of overheating. Indeed, with $100 \%$ of oversizing the system is overheated during more than 110 hours (temperature over $90^{\circ} \mathrm{C}$ at the top of the solar tank, which shuts down the solar pump). The recirculation loop connection to solar tank limits the overheating time to 30 hours but doesn't prevent it completely. The temperature occurrences over $90^{\circ} \mathrm{C}$ at the outlet of the solar collector are studied to understand which triggers overheating. The criticality of these occurrences is evaluated in the same way as cold water plug flows inside the recirculation loop: duration and amplitude (deviation from $90^{\circ} \mathrm{C}$ ). The results are shown in Figure 16. Two categories can be distinguished:

- Small amplitude (under $20^{\circ} \mathrm{C}$ ): the fluid tends to slowly heat through each passing inside the collectors. The amplitude is limited and the duration remains under 4 hours.

- $\quad$ High amplitude (over $20^{\circ} \mathrm{C}$ ): the maximum temperature grows quickly. This occurs when the solar pump shuts down. The fluid inside the collector is thus stagnant and is severely heated. The recirculation linking to solar tank reduces the occurrence and duration of these episodes, however the maximal amplitude remains the same.
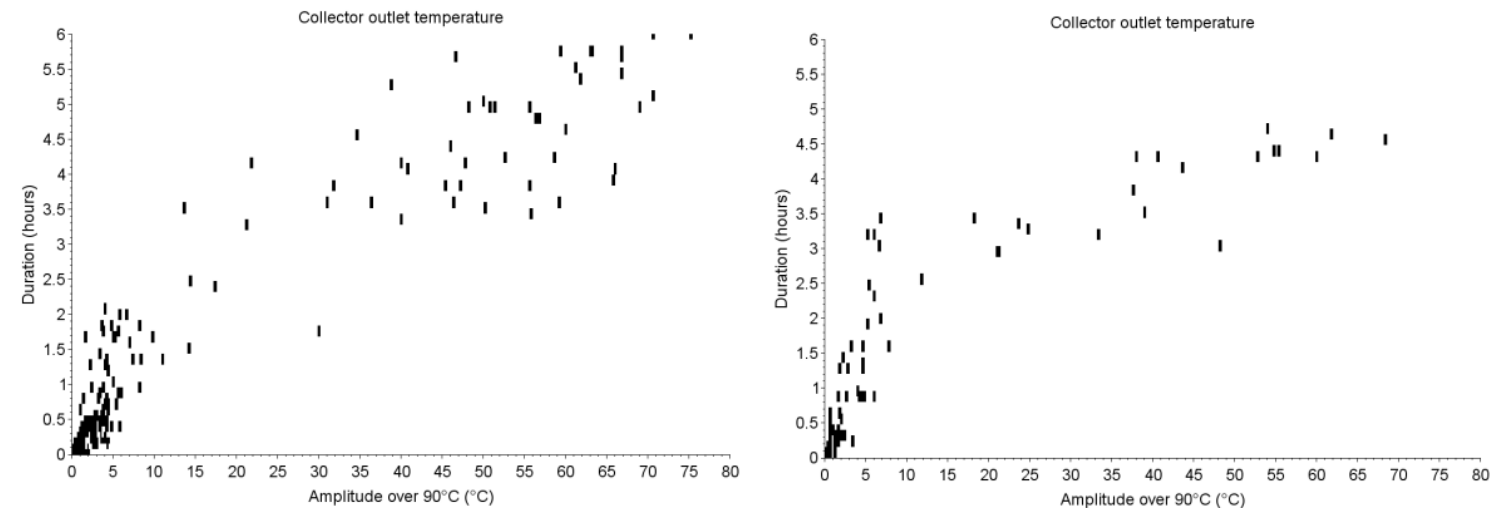

Figure 16 - Overheating cycle repartition in duration and amplitude with (right) and without (left) recirculation link to solar tank for $100 \%$ oversized solar collector

A corresponding criticality criterion can be computed for durability risks caused by overheating, as defined in Table 3. 
In the case of $100 \%$ oversizing compared to the reference system, adding the recirculation loop connection to solar tank reduces the criticality from $11527 \mathrm{~h} .{ }^{\circ} \mathrm{C}$ to $3518 \mathrm{~h} .{ }^{\circ} \mathrm{C}$.

- Temperatures and flow rates analysis for specific time window for reference and recirculation loop models and collector surface oversizing factor set at $100 \%$.

However, not all overheating cycles are prevented with the recirculation loop connection to the solar tank. The reason for that lack of efficiency when high temperature is reached is seen in Figure 17. It represents auxiliary tank top and bottom (full line - red and green respectively) temperatures, solar tank top temperature (dashed line - blue), flow rate through auxiliary tank from solar tank (dashed-dotted line - magenta) and from recirculation loop (dotted line - cyan).
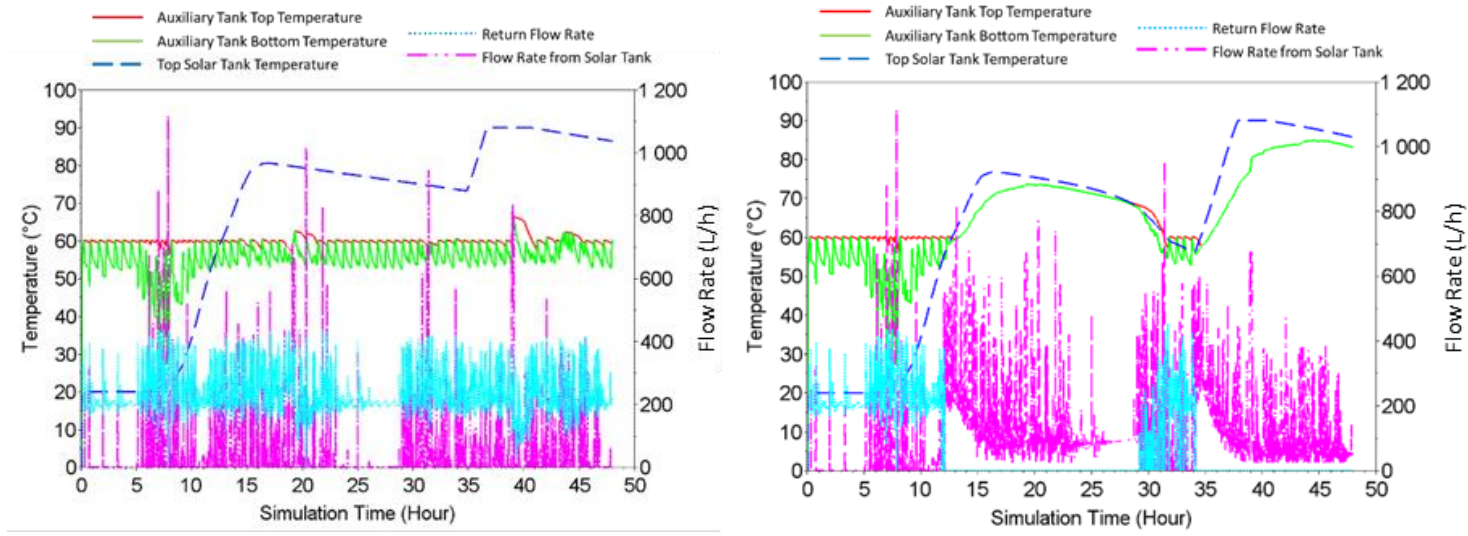

Figure 17 - Simulation results for 2 days (July $29^{\text {th }}$ and $30^{\text {th }}$ ) with (right) and without (left) recirculation linking to solar tank for $100 \%$ of oversized solar collector

Without recirculation link to solar tank (Figure 17, left), the recirculation water flow enters the auxiliary tank at $51^{\circ} \mathrm{C}$. Whatever the solar tank temperature, the volume coming from the recirculation loop is a lot greater than the one coming from the hot solar tank, which is linked to user draw-offs (reduced in summer following DHWCalc configuration). Thus, the auxiliary tank top temperature remains usually around $60^{\circ} \mathrm{C}$. However, when the recirculation loop is connected to the solar tank (Figure 17, right), and if the latter is at high temperature, water flowing through the auxiliary tank comes entirely from the solar tank. Due to its small volume, the auxiliary tank temperature quickly follows the solar tank top temperature. For example, it exceeds $80^{\circ} \mathrm{C}$ at the end of the second day. Since such high temperature water reaches the mixing device hot entrance, the need for cold water is greatly increased to ensure $55^{\circ} \mathrm{C}$ at the mixing valve outlet. This explains the decreased flow rate coming from the solar tank as the auxiliary top temperature increases. In this case, the solar tank cooling is reduced because a greater part of the cold water skips the tanks to flow directly through the mixing device cold entrance.

- $\quad 7$ \& 8- Annual Energy and Durability performance with solar recirculation loop, $100 \%$ collector surface oversizing and with differential temperature threshold set at $4^{\circ} \mathrm{C}\left(n^{\circ} 7\right)$ or $15^{\circ} \mathrm{C}\left(n^{\circ} 8\right)$

Durability must be ensured for the 3-way diverting valve. When the recirculation return to the solar tank is added to the reference system, the valve achieves more than 5300 cycles per year. A cycle is defined as the course of the valve for changing from the position where all water flows to the auxiliary tank, then to the one where full flow goes entirely to the solar tank, then return to initial position. More than $90 \%$ of these cycles last less than 5 minutes. Figure 18 shows the cycle duration statistics for two different mixing valve response time. 


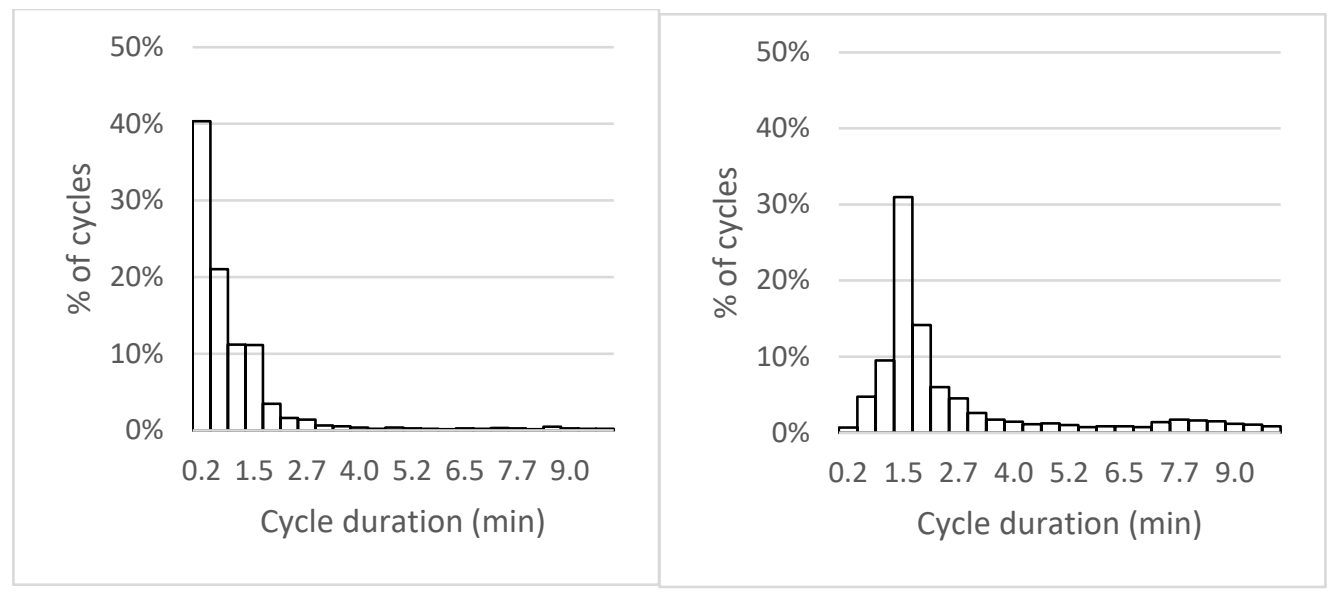

Figure 18 - Recirculation 3-way valve cycle durations for mixing valve response time of 30 seconds (left) and 10 minutes (right)

Indeed, the cycle time seems fully linked to the cold plug flow durations as represented in Figure 13. The majority of cycles lasts less than the mixing valve response time, with a peak for slow response time corresponding to the draw-off usual duration: 1 minute. This is due to the response of the recirculation valve control to cold plug flows. This quick temperature decrease may lead to a recirculation return colder than the solar tank top temperature and thus changes the valve position. With an ideal mixing valve (no response time), there are only 150 recirculation 3-way valve cycles for the whole year.

Increasing the differential temperature threshold needed before sending the recirculation return to the solar tank prevents such issues. Indeed, when it is set to $15^{\circ} \mathrm{C}$, over most cold plug flow amplitudes, the number of cycles is limited to 250 . The consequent loss in energy performance is then limited to $1 \%$.

\section{Conclusion}

Looking at multiple cases, solar thermal DHW systems for multifamily buildings may show modest performances on various aspects as the energetic efficiency, sanitary risks or components durability. Through the development of high time resolution model on TRNSYS, the impact of multiple design and sizing parameters on the different criteria have been quantitatively evaluated in this work, while they were previously unknown.

A new TRNSYS component, aiming at dynamic recirculation flow prediction during the draw-offs, has been developed and validated with actual measurements on a real, large scale, solar thermal plant in France. It shows that the recirculation flow decreases when users are drawing hot water. It also demonstrates that dynamic effects at small time scale have an impact on system performance and must be taken into account during designing and sizing stages. Moreover, energetic performance is not the only criteria that must be considered as other aspects are relevant: using a mixing valve with an actual 10 minutes response time rather than 30 seconds leads to a slight decrease in fsav (3.5\%). However, the legionella growth risk is increased by $300 \%$ as the criticality of cold plug flows generated by the mixing device depends on its own response time and on draw-offs durations. Thus, fast response mixing valve should be favored to improve fractional energy savings and to limit legionella risk.

Another element that may impair system global performance is the modification of some key parameters. The study emphasizes that energy savings is reduced by $7 \%$ to $10 \%$ when auxiliary set-point temperature is increased, or recirculation pump is oversized. Indeed, any measure that tends to increase temperature at mixing device inputs is lowering energy savings due to a reduced volume of cold water flowing through the solar tank. It emphasizes the requirement to check that no parameters have been inconsistently modified during periodic maintenance.

As anticipated and put forward by many stakeholders like SOCOL professional group in France, recirculation return connection to solar tank fulfills its positive consequences: increase in energy savings and reduction of overheating period criticality. The gain is limited in the optimized reference case, however it becomes significant when the solar production is oversized in comparison with the load. Indeed, the fractional energy savings gain is $15 \%$ when collector surface is doubled while constant hot water consumption profile, versus $6 \%$ with the reference system. Moreover, overheating related risks are reduced by a factor of 3. Solar system oversizing improves energetic performances and is thus an appropriate solution to increase the share of solar energy in DHW need, yet a balance must be found as durability risks increase as well. 
One reason of this impact on durability is the self-limitation of the recirculation loop connection to solar tank because of interferences with the mixing device.

Lastly, three-way valve durability is ensured if the differential temperature threshold chosen is higher than the cold plug flows maximal amplitude, about $15{ }^{\circ} \mathrm{C}$ in the reference system.

The results obtained through numeric analysis confirmed the experts' perceptions on real installations as the subjects of system sanitary risks and durability are the new priorities of the sector. This work's perspective is to enlarge the scope of the study to solar thermal plant using plate heat exchanger to isolate buffer tank and sanitary water loop widespread in solar thermal plants for hospital or senior residents building sector.

\section{Acknowledgements:}

This research has been performed with the support of INES Plateforme Formation Evaluation team (G.Pradier, X.Cholin and X.Rauscher) that offered challenging discussions of the results and provided access to real large DHW solar plant in operation for the experimental measurement work.

\section{Nomenclature:}

\begin{tabular}{|c|c|c|}
\hline$Q_{D H W C a l c}$ & $\mathrm{~L} / \mathrm{h}$ & Draw-off volumetric flow rate from DHWCalc (at $45^{\circ} \mathrm{C}$ ) \\
\hline$Q_{D H W}$ & $\mathrm{~L} / \mathrm{h}$ & Draw-off volumetric flow rate adapted at $53^{\circ} \mathrm{C}$ \\
\hline$Q_{\text {rec }}$ & $\mathrm{L} / \mathrm{h}$ & Recirculation flow rate \\
\hline$Q_{\text {rec }}^{\prime}$ & $\mathrm{L} / \mathrm{h}$ & Recirculation flow rate new Type solution before relaxation \\
\hline$Q_{\text {sol }}$ & $L / h$ & Solar loop flow rate \\
\hline$Q_{\text {Draw }}$ & L/h & Draw-off flow rate \\
\hline$T_{\text {cold-mean }}$ & ${ }^{\circ} \mathrm{C}$ & Mean cold water temperature \\
\hline$T_{\text {cold }}$ & ${ }^{\circ} \mathrm{C}$ & Cold water temperature \\
\hline$T_{\text {mix }}$ & ${ }^{\circ} \mathrm{C}$ & Instantaneous mixer temperature \\
\hline$T_{\text {set }}$ & ${ }^{\circ} \mathrm{C}$ & Mixer set point \\
\hline$e(t)$ & ${ }^{\circ} \mathrm{C}$ & Temperature error at mixer output \\
\hline$T_{c-o u t}$ & ${ }^{\circ} \mathrm{C}$ & Solar collector outlet temperature \\
\hline$T_{c-i n}$ & ${ }^{\circ} \mathrm{C}$ & Solar collector inlet temperature \\
\hline$T_{D H W}$ & ${ }^{\circ} \mathrm{C}$ & Delivered hot water temperature \\
\hline$P_{\text {sol }}$ & W & Recovered solar power at the collector \\
\hline$P_{\text {aux }}$ & W & Power delivered by the auxiliary system \\
\hline$\varepsilon \boldsymbol{P}_{\text {elec }}$ & W & Share of pump electrical power consumption converted into thermal power \\
\hline$P_{D H W}$ & W & Power delivered to the user \\
\hline$P_{\text {Loss-Sol }}$ & W & Heat loss in solar loop \\
\hline$P_{\text {Loss-StoSol }}$ & W & Heat loss in solar tank \\
\hline$P_{\text {Loss-StoAux }}$ & W & Heat loss in auxiliary tank \\
\hline$P_{\text {Loss }-D H W}$ & W & Heat loss in recirculation loop \\
\hline$E_{\text {sol }}$ & $\mathrm{kJ}$ & Recovered solar energy at the collector \\
\hline$E_{\text {aux }}$ & $\mathrm{kJ}$ & Delivered energy by auxiliary heating \\
\hline$\Delta E_{S t o}$ & $\mathrm{~kJ}$ & Internal energy change \\
\hline$\delta$ & $\mathrm{kJ}$ & Energy balance error \\
\hline$C_{E P}$ & $\mathrm{~kJ}$ & Gross energy consumption of the studied system \\
\hline$C_{E P, G a s}$ & $\mathrm{~kJ}$ & Gross energy consumption of gas-only system \\
\hline$\Delta P_{\text {reg }}$ & $\mathrm{Pa}$ & Regular pressure drop \\
\hline$\Delta P_{\text {sing }}$ & $\mathrm{Pa}$ & Singular pressure drop \\
\hline$\Delta P_{\text {reg-toDelivery }}$ & $\mathrm{Pa}$ & Regular pressure drop between the mixer and the draw-off location \\
\hline$\Delta \boldsymbol{P}_{\text {reg-return }}$ & $\mathrm{Pa}$ & Regular pressure drop between the draw-off location and the storage \\
\hline$\Delta P_{\text {tot }}$ & $\mathrm{Pa}$ & Total pressure drop \\
\hline fsav & - & Fractional energy savings \\
\hline$L$ & $\mathrm{~m}$ & Pipe length \\
\hline $\boldsymbol{D}$ & $\mathrm{m}$ & Pipe hydraulic diameter \\
\hline$\varepsilon$ & $\mathrm{m}$ & Surface roughness \\
\hline$l_{e q}$ & $\mathrm{~m}$ & Singular drops equivalent pipe length \\
\hline$\rho$ & kg. $\mathrm{m}^{-3}$ & Fluid density \\
\hline
\end{tabular}




\begin{tabular}{|c|c|c|}
\hline $\boldsymbol{v}$ & $\mathrm{m} \cdot \mathrm{s}^{-1}$ & Fluid velocity \\
\hline$c_{p-c a l o}$ & $\mathrm{~J} \cdot \mathrm{kg}^{-1} \cdot{ }^{\circ} \mathrm{C}^{-1}$ & Heat transfer fluid capacity \\
\hline$c_{p-D H W}$ & $\mathrm{~J} \cdot \mathrm{kg}^{-1} \cdot{ }^{\circ} \mathrm{C}^{-1}$ & Domestic Hot Water heat capacity \\
\hline $\boldsymbol{R e}_{\mathrm{D}}$ & - & Reynolds number \\
\hline$f$ & - & Friction coefficient \\
\hline$\omega$ & - & Relaxation factor \\
\hline$\zeta_{u}$ & - & Singular pressure drop coefficient \\
\hline $\boldsymbol{v}$ & $\mathrm{m}^{2} \cdot \mathrm{s}^{-1}$ & Cinematic viscosity \\
\hline $\boldsymbol{K}$ & - & PI controller proportional coefficient for mixer model \\
\hline$T_{i}$ & $\mathrm{~h}$ & PI controller integral time coefficient for mixer model \\
\hline$c(t)$ & - & Mixing valve control \\
\hline$R_{p l u g}$ & h. ${ }^{\circ} \mathrm{C}$ & Legionella growth criticality criteria \\
\hline$\Delta t_{p l u g}$ & h & Cold plug flow duration \\
\hline$\Delta T_{p l u g}$ & ${ }^{\circ} \mathrm{C}$ & Maximal deviation from $50^{\circ} \mathrm{C}$ \\
\hline$R_{\text {over }}$ & h. ${ }^{\circ} \mathrm{C}$ & Overheating criticality criteria \\
\hline$\Delta t_{\text {over }}$ & $\mathrm{h}$ & Collector outlet temperature over $90^{\circ} \mathrm{C}$ period duration \\
\hline$\Delta T_{\text {over }}$ & ${ }^{\circ} \mathrm{C}$ & Collector outlet temperature over $90^{\circ} \mathrm{C}$ period maximal deviation from $90^{\circ} \mathrm{C}$ \\
\hline CEA & - & "Commissariat à l'Energie Atomique" \\
\hline CFD & - & Computational Fluid Dynamics \\
\hline DHW & - & Domestic Hot Water \\
\hline IEA & - & International Energy Agency \\
\hline IPCC & - & Intergovernmental Panel on Climate Change \\
\hline PI & - & Proportional Integral Controller \\
\hline SDHW & - & Solar Domestic Hot Water \\
\hline
\end{tabular}

\section{References:}

ADEME, 2018. Les besoins d'eau chaude sanitaire en habitat individuel et collectif [WWW Document]. URL https://www.precarite-energie.org/IMG/pdf/besoin-eau-chaude-sanitaire-habitat-individuel-et-collectif8809.pdf (accessed 7.24.18).

AFNOR, 2018. EN 12977-2.

AFNOR, 2013. NF DTU 60.11.

AFNOR, 2008. NF EN 15092.

Al-Habaibeh, A., Shakmak, B., Fanshawe, S., 2018. Assessment of a novel technology for a stratified hot water energy storage - The water snake. Appl. Energy 222, 189-198. https://doi.org/10.1016/j.apenergy.2018.04.014

Altuntop, N., Arslan, M., Ozceyhan, V., Kanoglu, M., 2005. Effect of obstacles on thermal stratification in hot water storage tanks. Appl. Therm. Eng. 25, 2285-2298. https://doi.org/10.1016/j.applthermaleng.2004.12.013

Arrêté du 30 novembre 2005 modifiant l'arrêté du 23 juin 1978 relatif aux installations fixes destinées au chauffage et à l'alimentation en eau chaude sanitaire des bâtiments d'habitation, des locaux de travail ou des locaux recevant du public, n.d.

Bernardo, L.R., Davidsson, H., Karlsson, B., 2012. Retrofitting Domestic Hot Water Heaters for Solar Water Heating Systems in Single-Family Houses in a Cold Climate: A Theoretical Analysis. Energies 5, 41104131. https://doi.org/10.3390/en5104110

COSTIC, 2014. Installation d'eau chaude sanitaire: confort, prévention des risques et maitrise des consommations.

COSTIC, CSTB, EDF, TECSOL, 2019. Intégration du solaire thermique dans le secteur médico-social : analyses et préconisations.

Dentz, J., Ansanelli, E., Henderson, H., Varshney, K., 2016. Control Strategies to Reduce the Energy Consumption of Central Domestic Hot Water Systems [WWW Document]. URL https://www.nrel.gov/docs/fy16osti/64541.pdf (accessed 6.12.18).

Dickinson, R.M., Cruickshank, C.A., Harrison, S.J., 2013. Charge and discharge strategies for a multi-tank thermal energy storage. Appl. Energy 109, 366-373. https://doi.org/10.1016/j.apenergy.2012.11.032 
Dongellini, M., Falcioni, S., Morini, G.L., 2015. Dynamic Simulation of Solar Thermal Collectors for Domestic Hot Water Production. Energy Procedia, 70th Conference of the Italian Thermal Machines Engineering Association, ATI2015 82, 630-636. https://doi.org/10.1016/j.egypro.2015.12.012

Edwards, S., Beausoleil-Morrison, I., Laperrière, A., 2015. Representative hot water draw profiles at high temporal resolution for simulating the performance of solar thermal systems. Sol. Energy 111, 43-52. https://doi.org/10.1016/j.solener.2014.10.026

Geoghegan, G., Lior, N., 1984. A comparative economic analysis of straight-through and recirculation solar hot water systems. Energy 9, 53-63. https://doi.org/10.1016/0360-5442(84)90076-8

Ghorab, M., Entchev, E., Yang, L., 2017. Inclusive analysis and performance evaluation of solar domestic hot water system (a case study). Alex. Eng. J. 56, 201-212. https://doi.org/10.1016/j.aej.2017.01.033

Gunjo, D.G., Mahanta, P., Robi, P.S., 2017. CFD and experimental investigation of flat plate solar water heating system under steady state condition. Renew. Energy 106, 24-36. https://doi.org/10.1016/j.renene.2016.12.041

Hobbi, A., Siddiqui, K., 2009. Optimal design of a forced circulation solar water heating system for a residential unit in cold climate using TRNSYS. Sol. Energy 83, 700-714. https://doi.org/10.1016/j.solener.2008.10.018

Home Page | www.scilab.org [WWW Document], n.d. URL https://www.scilab.org/ (accessed 7.7.19).

IEA, 2018. Renewables 2018 : market analysis and forecast from 2018 to 2023.

IPCC, 2014. Climate Change 2014, Synthesis Report.

JEPlus Website [WWW Document], n.d. URL http://www.jeplus.org/wiki/doku.php (accessed 9.6.18).

Jordan, U., Vajen, K., 2001a. Realistic Domestic Hot-Water Profiles in Different Time Scales.

Jordan, U., Vajen, K., 2001b. Influence Of The DHW Load Profile On The Fractional Energy Savings:: A Case Study Of A Solar Combi-System With TRNSYS Simulations. Sol. Energy, EUROSUN 2000 Selected Proceedings 69, 197-208. https://doi.org/10.1016/S0038-092X(00)00154-7

Kim, J.H., Lee, U.J., Li, L., Kim, C., Hong, H., 2016. Improvement of collection efficiency and solar fraction in solar thermal storage system using a 3-way valve and a 2-stage flowrate control. J. Mech. Sci. Technol. 30, 3347-3356. https://doi.org/10.1007/s12206-016-0644-1

Knudsen, Sø., 2002. Consumers' influence on the thermal performance of small SDHW systems-Theoretical investigations. Sol. Energy 73, 33-42. https://doi.org/10.1016/S0038-092X(02)00018-X

Lämmle, M., Oliva, A., Hermann, M., Kramer, K., Kramer, W., 2017. PVT collector technologies in solar thermal systems: A systematic assessment of electrical and thermal yields with the novel characteristic temperature approach. Sol. Energy 155, 867-879. https://doi.org/10.1016/j.solener.2017.07.015

Lomet, A., Suard, F., Chèze, D., 2015. Statistical Modeling for Real Domestic Hot Water Consumption Forecasting. Energy Procedia, International Conference on Solar Heating and Cooling for Buildings and Industry, SHC 2014 70, 379-387. https://doi.org/10.1016/j.egypro.2015.02.138

Missoum, M., Hamidat, A., Imessad, K., Bensalem, S., Khodja, A., 2016. Energy performance investigation of a solar water heating system for single-family houses in Mediterranean climate, in: 2016 7th International Renewable Energy Congress (IREC). Presented at the 2016 7th International Renewable Energy Congress (IREC), pp. 1-6. https://doi.org/10.1109/IREC.2016.7478943

Papillon, P., Paulus, C., Chèze, D., Lefrançois, F., 2014. A Simplified Design Tool for Solar DHW Systems in Multi-family Houses with Decentralized Storages. Energy Procedia 48, 757-767. https://doi.org/10.1016/j.egypro.2014.02.088

Porcheyre, E., 2017. Synthèse Etats Généraux de la Chaleur Solaire 2017 (Synthèse), Etats Généraux de la Chaleur Solaire. Enerplan, Paris, France.

Pradier, G., 2018. Rapport TéléSuiWeb (Rapport d'analyse). INES Plateforme Formation Evaluation.

Prapas, D.E., Tsiamouris, S.G., Giannaros, V.D., Sotiropoulos, B.A., 1993. Storage tanks interconnection and operation modes in large DHW solar systems. Sol. Energy 51, 83-91. https://doi.org/10.1016/0038092X(93)90070-5

Ramonet, C., Sahraoui, N., 2018. Retour d'expérience de la Société Dauphinoise Habitat SDH.

Recknagel, H., Sprenger, E., Schmarek, E.-R., 2005. Génie Climatique. Dunod.

SHC - IEA, 2018. Solar Heat Worldwide [WWW Document]. URL http://www.ieashc.org/Data/Sites/1/publications/Solar-Heat-Worldwide-2018.pdf (accessed 7.26.18).

Shrivastava, R.L., Vinod Kumar, Untawale, S.P., 2017. Modeling and simulation of solar water heater: A TRNSYS perspective. Renew. Sustain. Energy Rev. 67, 126-143. https://doi.org/10.1016/j.rser.2016.09.005

SOCOL, 2017. SOCOL - Solaire Thermique Collectif et chaleur solaire collective [WWW Document]. URL https://www.solaire-collectif.fr/actu-socol/18/fondamentaux-st-coll.htm (accessed 7.25.18).

Spur, R., Fiala, D., Nevrala, D., Probert, D., 2006. Influence of the domestic hot-water daily draw-off profile on the performance of a hot-water store. Appl. Energy 83, 749-773. https://doi.org/10.1016/j.apenergy.2005.07.001

Szebeszczyk, J.M., 1994. Application of clamp-on ultrasonic flowmeter for industrial flow measurements. Flow Meas. Instrum. 5, 127-131. https://doi.org/10.1016/0955-5986(94)90047-7 
THERMADOR, 2017. Mitigeurs Thermostatique JRG34.

TRNSYS [WWW Document], n.d. URL http://www.trnsys.com/ (accessed 9.6.18).

Zainine, M.A., Mezni, T., Dakhlaoui, M.A., Guizani, A., 2017. Energetic performance and economic analysis of a solar water heating system for different flow rates values: A case study. Sol. Energy 147, 164-180. https://doi.org/10.1016/j.solener.2017.03.038 